\title{
Societal shifts due to COVID-19 reveal large-scale complexities and feedbacks between atmospheric chemistry and climate change
}

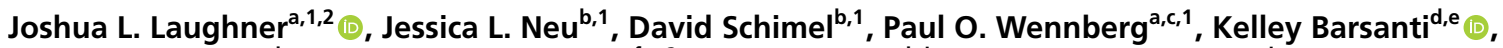

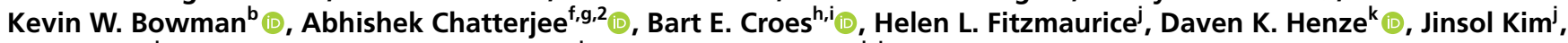 \\ Eric A. Kort ${ }^{\top}$, Zhu Liu ${ }^{\mathrm{m}}$, Kazuyuki Miyazaki ${ }^{\mathrm{b}}$, Alexander J. Turner ${ }^{\mathrm{b}, \mathrm{j}, \mathrm{n}}{ }^{\circ}$, Susan Anenberg ${ }^{\circ} \odot$, Jeremy Avise $^{\mathrm{p}}$,

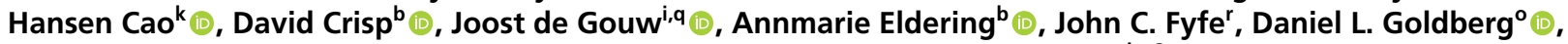

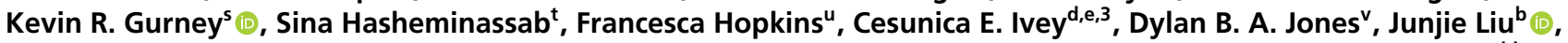

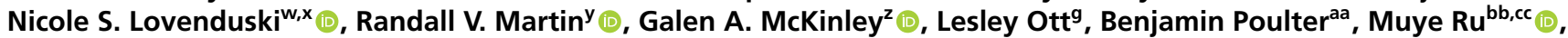

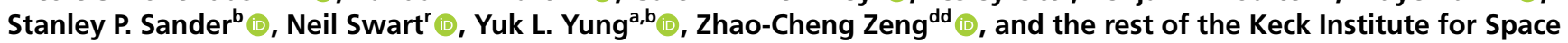 \\ Studies "COVID-19: Identifying Unique Opportunities for Earth System Science" study team ${ }^{4}$
}

${ }^{a}$ Division of Geological and Planetary Sciences, California Institute of Technology, Pasadena, CA 91125; ${ }^{\mathrm{b}}$ Jet Propulsion Laboratory, California Institute of Technology, Pasadena, CA 91109; 'Division of Engineering and Applied Science, California Institute of Technology, Pasadena, CA 91125; ${ }^{\mathrm{d} D e p a r t m e n t}$ of Chemical and Environmental Engineering, University of California, Riverside, CA 92521; ${ }^{\circ}$ Center for Environmental Research and Technology, Riverside, CA 92507; ${ }^{f}$ Goddard Earth Sciences Technology and Research, Universities Space Research Association, Columbia, MD $21046 ;{ }^{9} \mathrm{Global}$ Modeling and Assimilation Office, NASA Goddard Space Flight Center, Greenbelt, MD 20771; ${ }^{\mathrm{h}}$ Energy Research and Development Division, California Energy Commission,

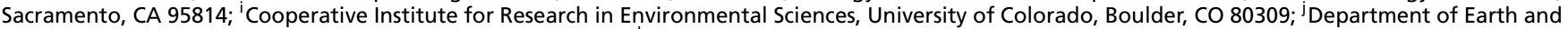
Planetary Science, University of California, Berkeley, CA 94720; ${ }^{k}$ Department of Mechanical Engineering, University of Colorado, Boulder, CO 80309; 'Department of Climate and Space Sciences and Engineering, University of Michigan, Ann Arbor, MI 48109; ${ }^{\mathrm{m}}$ Department of Earth System Science, Tsinghua University, Beijing 100084, China; ${ }^{\mathrm{n}}$ Department of Atmospheric Sciences, University of Washington, Seattle, WA 98195; ${ }^{\circ}$ Milken Institute School of Public Health, George Washington University, Washington, DC 20052; ${ }^{\mathrm{P}}$ Modeling and Meteorology Branch, California Air Resources Board, Sacramento, CA 95814; ' Department of Chemistry, University of Colorado, Boulder, CO 80309; ' Canadian Centre for Climate Modelling and Analysis, Environment and Climate Change Canada, Victoria, BC, V8W 2Y2 Canada; ${ }^{5}$ School of Informatics, Computing, and Cyber Systems, Northern Arizona University, Flagstaff, AZ 86011; ${ }^{t}$ Science and Technology Advancement Division, South Coast Air Quality Management District, Diamond Bar, CA, 91765; ${ }^{u}$ Department of Environmental Sciences, University of California, Riverside, CA 92521; ' Department of Physics, University of Toronto, Toronto, ON, M5S 1 A1 Canada; ${ }^{w}$ Department of Atmospheric and Oceanic Sciences, University of Colorado, Boulder, CO 80309; ${ }^{\mathrm{x}}$ Institute of Arctic and Alpine Research, University of Colorado, Boulder, CO 80309; ${ }^{y}$ McKelvey School of Engineering, Washington University in St. Louis, St. Louis, MO 63130; ${ }^{\mathrm{D} D e p a r t m e n t}$ of Earth and Environmental Sciences, Lamont Doherty Earth Observatory, Columbia University, Palisades, NY 10964; ${ }^{a}$ Biospheric Sciences Laboratory, NASA Goddard Space Flight Center, Greenbelt, MD 20771; ${ }^{\text {bb }}$ The Earth Institute, Columbia University, New York, NY 10025; ${ }^{c}$ Nicholas School of the Environment, Duke University, Durham, NC 27707; and dd Joint Institute for Regional Earth System Science and Engineering, University of California, Los Angeles, CA 90095

Edited by Akkihebbal R. Ravishankara, Colorado State University, Fort Collins, CO, and approved September 29, 2021 (received for review June 10, 2021)

The COVID-19 global pandemic and associated government lockdowns dramatically altered human activity, providing a window into how changes in individual behavior, enacted en masse, impact atmospheric composition. The resulting reductions in anthropogenic activity represent an unprecedented event that yields a glimpse into a future where emissions to the atmosphere are reduced. Furthermore, the abrupt reduction in emissions during the lockdown periods led to clearly observable changes in atmospheric composition, which provide direct insight into feedbacks between the Earth system and human activity. While air pollutants and greenhouse gases share many common anthropogenic sources, there is a sharp difference in the response of their atmospheric concentrations to COVID-19 emissions changes, due in large part to their different lifetimes. Here, we discuss several key takeaways from modeling and observational studies. First, despite dramatic declines in mobility and associated vehicular emissions, the atmospheric growth rates of greenhouse gases were not slowed, in part due to decreased ocean uptake of $\mathrm{CO}_{2}$ and a likely increase in $\mathrm{CH}_{4}$ lifetime from reduced $\mathrm{NO}_{x}$ emissions. Second, the response of $\mathrm{O}_{3}$ to decreased $\mathrm{NO}_{x}$ emissions showed significant spatial and temporal variability, due to differing chemical regimes around the world. Finally, the overall response of atmospheric composition to emissions changes is heavily modulated by factors including carbon-cycle feedbacks to $\mathrm{CH}_{4}$ and $\mathrm{CO}_{2}$, background pollutant levels, the timing and location of emissions changes, and climate feedbacks on air quality, such as wildfires and the ozone climate penalty.

COVID-19 | air quality | greenhouse gases | earth system | mitigation

$\mathbf{T}$ he effects of the COVID-19 pandemic and associated lockdown measures have provided a way to observationally test predictions of future atmospheric composition. This is illustrated conceptually in Fig. 1. With many people working from home and limiting travel, the pandemic caused a significant decrease in anthropogenic emissions. These emissions reductions can be thought of as a jump forward in time to a future where additional systemic emissions controls have been adopted. However, because these changes occurred in a matter of months, the changes to the concentrations of key air quality (AQ) and climate-relevant gases in the atmosphere were readily observable. Combining these observations with current state-of-science models allows us an important window into the underlying processes governing

Author contributions: J.L.L., K.B., K.W.B., A.C., B.E.C., H.L.F., D.K.H., J.K., E.A.K., Z.L., K.M A.J.T., S.A., J.A., H.C., D.C., J.d.G., A.E., J.C.F., D.L.G., K.R.G., S.H., F.H., C.E.I., D.B.A.J., J.L., N.S.L., R.V.M., G.A.M., L.O., B.P., M.R., S.P.S., N.S., Y.L.Y., and Z.-C.Z. performed research J.L.N., D.S., and P.O.W. designed research; J.L.L., J.L.N., D.S., P.O.W., K.B., K.W.B., A.C., B.E.C., H.L.F., D.K.H., J.K., E.A.K., Z.L., K.M., A.J.T., S.A., J.A., H.C., D.C., J.d.G., A.E., J.C.F., D.L.G., K.R.G., S.H., F.H., C.E.I., D.B.A.J., J.L., N.S.L., R.V.M., G.A.M., L.O., B.P., M.R., S.P.S., N.S., Y.L.Y., and Z.-C.Z. analyzed data; J.L.L., J.L.N., D.S., and P.O.W. wrote the paper; and K.B., K.W.B., A.C., B.E.C., H.L.F., D.K.H., J.K., E.A.K., Z.L., K.M., A.J.T., S.A., J.A., H.C., D.C., J.d.G., A.E., J.C.F., D.L.G., K.R.G., S.H., F.H., C.E.I., D.B.A.J., J.L., N.S.L., R.V.M., G.A.M., L.O., B.P., M.R., S.P.S., N.S., Y.L.Y., and Z.-C.Z. edited and approved the manuscript draft.

The authors declare no competing interest.

This article is a PNAS Direct Submission.

This open access article is distributed under Creative Commons Attribution NonCommercial-NoDerivatives License 4.0 (CC BY-NC-ND).

${ }^{1}$ To whom correspondence may be addressed. Email: jlaugh@caltech.edu, jessica.I.neu@jpl.nasa.gov, david.schimel@jpl.nasa.gov, or wennberg@gps.caltech.edu. ${ }^{2}$ Present address: Jet Propulsion Laboratory, California Institute of Technology, Pasadena, CA 91109.

${ }^{3}$ Present address: Department of Civil and Environmental Engineering, University of California, Berkeley, CA 94720

${ }^{4} \mathrm{~A}$ complete list of the Keck Institute for Space Studies "COVID-19: Identifying Unique Opportunities for Earth System Science" study team can be found in the SI Appendix.

This article contains supporting information online at https://www.pnas.org/lookup/ suppl/doi:10.1073/pnas.2109481118/-/DCSupplemental.

Published November 9, 2021. 


\section{Significance}

The COVID-19 pandemic and associated lockdowns caused significant changes to human activity that temporarily altered our imprint on the atmosphere, providing a brief glimpse of potential future changes in atmospheric composition. This event demonstrated key feedbacks within and between air quality and the carbon cycle: Improvements in air quality increased the lifetime of methane (an important greenhouse gas), while unusually hot weather and intense wildfires in Los Angeles drove poor air quality. This shows that efforts to reduce greenhouse gas emissions and improve air quality cannot be considered separately.

the response of the Earth system to reductions in anthropogenic emissions and thus a preview of the relative effectiveness of different emissions-control strategies.

Our goal is to synthesize some of the key results from the past year into a coherent understanding of what we have learned about the effectiveness of different strategies to reduce greenhouse gas (GHG) emissions and improve AQ. We briefly highlight individual components of the changes in composition (which are well-described in the literature) but focus on the interactions and feedbacks between different parts of the Earth system. We will do so in four parts. First, we summarize the observed changes in anthropogenic emissions during 2020. Second, we examine how the reduction in $\mathrm{CO}_{2}$ emissions impacted the atmospheric $\mathrm{CO}_{2}$ growth rate. Third, we show that the response of $\mathrm{AQ}$ to $\mathrm{NO}_{x}$ emissions reductions differs for cities around the world and depends strongly on the interaction with meteorology. We focus on ozone and nitrate particulate matter (PM) as key AQ metrics that are strongly driven by $\mathrm{NO}_{x}$ emissions. Fourth, we discuss the implications of these results for future AQ improvement strategies; our understanding of processes controlling GHG concentrations in the atmosphere; feedbacks between AQ, GHGs, and climate; and, finally, close by identifying strengths and gaps in our current observing networks. We draw three primary conclusions from this synthesis:

1. Despite drastic reductions in mobility and resulting vehicular emissions during 2020, the growth rates of GHGs in the atmosphere were not slowed.

2. The lack of clear declines in the atmospheric growth rates of $\mathrm{CO}_{2}$ and $\mathrm{CH}_{4}$, despite large reductions in human activity, reflect carbon-cycle feedbacks in air-sea carbon exchange, large interannual variability in the land carbon sink, and the chemical lifetime of $\mathrm{CH}_{4}$. These feedbacks foreshadow similar challenges to intentional mitigation.

3. The response of AQ to emissions changes is heavily modulated by factors including background pollutant levels, the timing and location of emissions changes, and climate-related factors like heat waves and wildfires. Achieving robust improvements to $\mathrm{AQ}$ thus requires sustained reductions of both air pollutant (AP) and GHG emissions.

\section{Summary of Emissions in $\mathbf{2 0 2 0}$}

As AQ-relevant gases and $\mathrm{CO}_{2}$ are coemitted by combustion processes, decreases in human activity are expected to drive

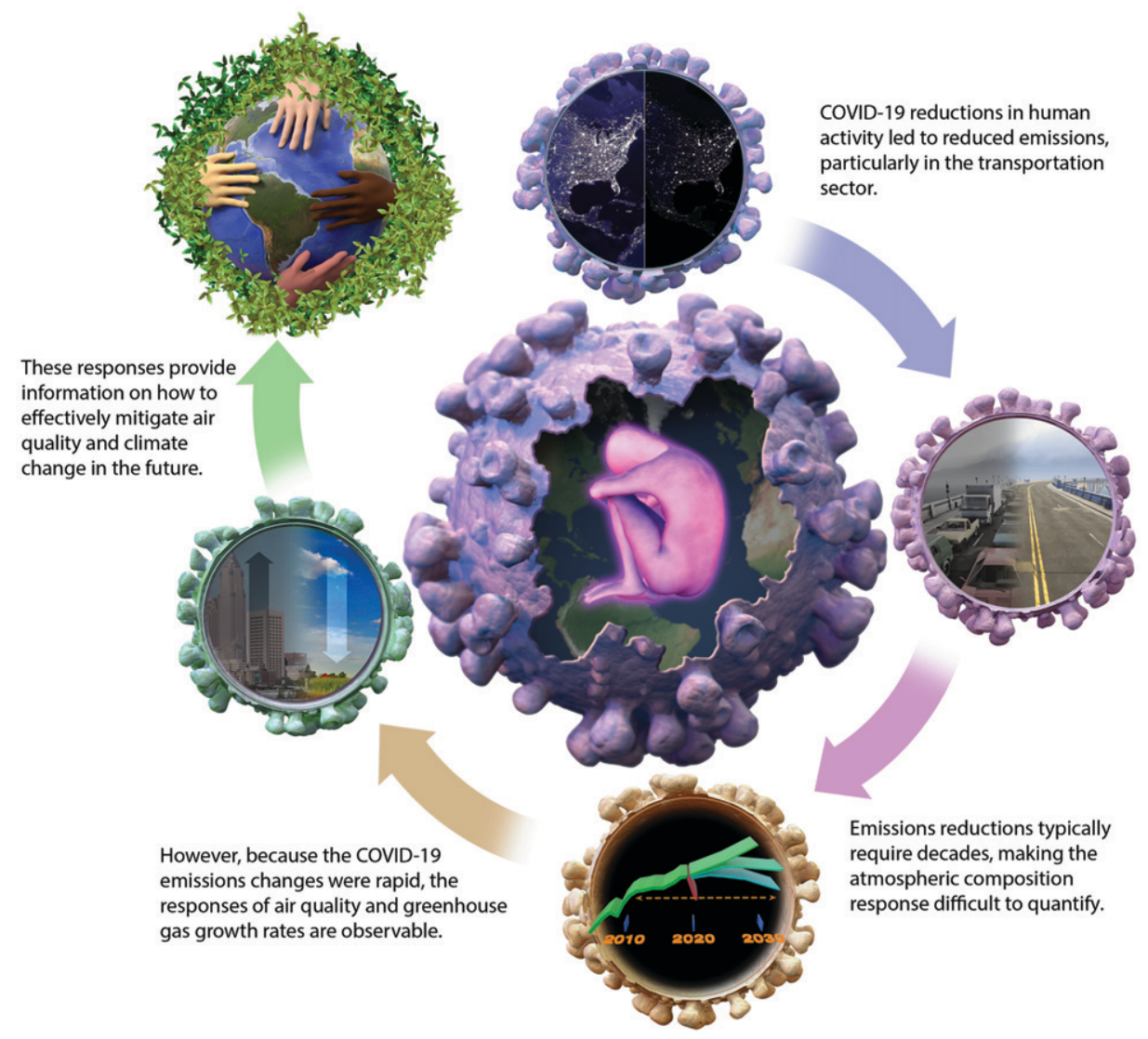

Fig. 1. Illustration of the conceptual foundation for this study. The COVID-19-induced reductions in human activity led to reduced anthropogenic emissions. The fact that these reductions occurred over months rather than decades allows us to observe how the atmosphere, land, and ocean are likely to respond in a future scenario with stricter emissions controls. This analysis helps to identify effective pathways to mitigate air pollution and climate-relevant GHG emissions. Image credit: Chuck Carter (Keck Institute for Space Studies, Pasadena, CA). 

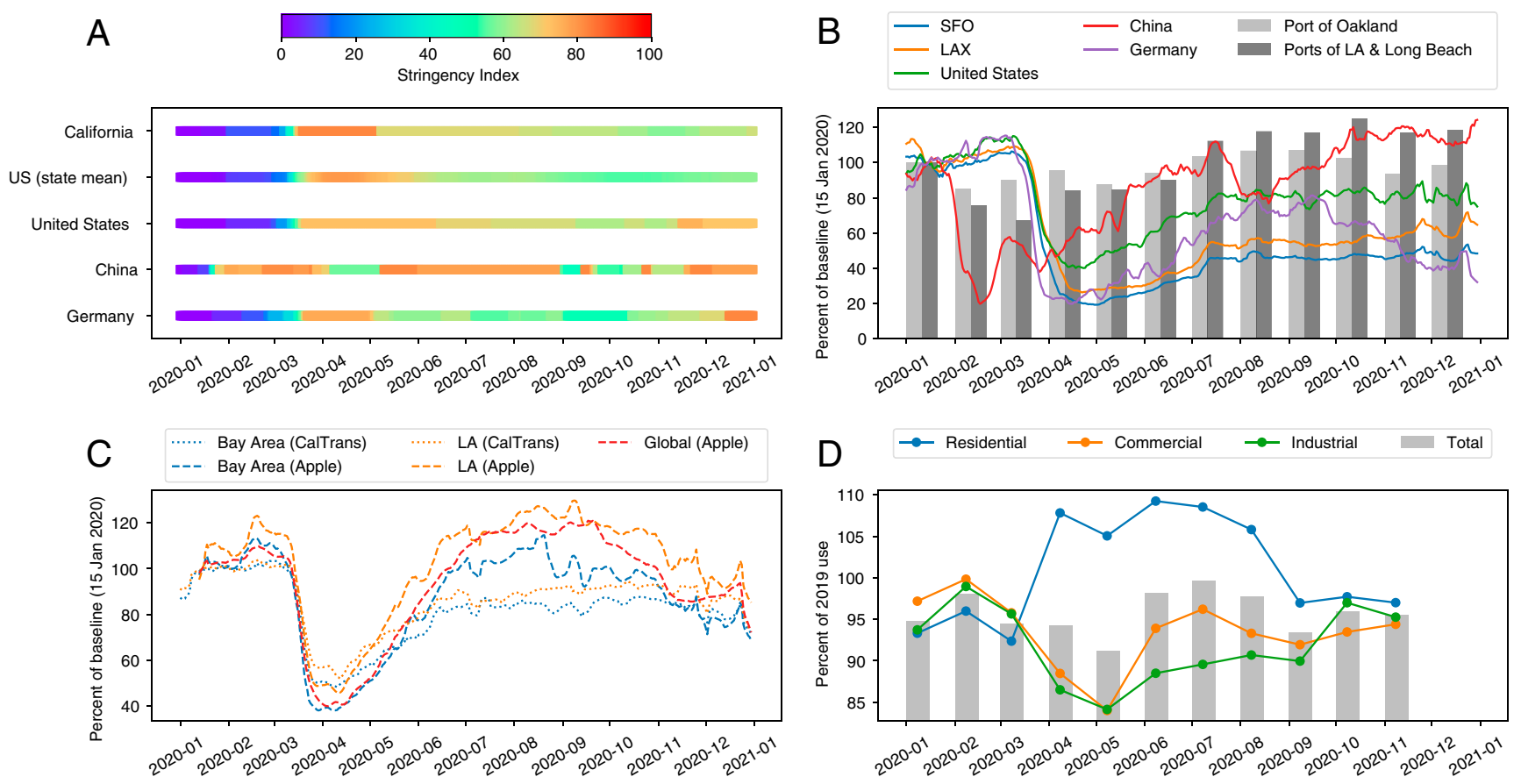

Fig. 2. Metrics for change in human activity at different scales show that the strongest impact of COVID-19 lockdowns was in the transportation sectors and that these impacts varied substantially from country to country. A shows the Oxford Stringency Index (1) for the regions used in this figure. "US (state mean)" is the average of individual states' indices, and "United States" is the index attributed to the United States as a whole (not individual states; see SI Appendix for discussion). B shows the percent change in flights (2-4) for two California airports (San Francisco International Airport [SFO] and Los Angeles International Airport [LAX]) and three countries (lines) and container moves for three California ports (bars). $C$ shows traffic metrics for two California urban areas and 26 countries ("global"). CalTrans indicates California Department of Transportation Performance Measurement System data; Apple indicates Apple driving mobility data. $D$ shows electricity consumption in the United States by sector, relative to the same month in 2019 . The three sectors shown constitute $>96 \%$ of US power consumption. In $B$ and $C$, daily metrics are relative to 15 January 2020 and presented as 7-d rolling averages, and monthly metrics are relative to January 2020. Electricity consumption was not available after November 2020 at the time of writing.

decreases in both of these species. Fig. 2 summarizes changes to key sectors of human activity during the COVID-19 pandemic. Fig. $2 A$ shows the Oxford Stringency Index (1), which quantifies the severity of government-imposed restrictions on travel, businesses, schools, and other aspects of society. Fig. 2 $B-D$ show changes in air travel and maritime shipping; traffic; and US electricity use, respectively. There was a clear decrease in air travel and traffic for most of the world in March 2020, when the first major wave of COVID-19 led governments to institute quarantine measures (see also high values of the Stringency Index). Maritime shipping (to West Coast US ports) and power generation (in the United States) were less affected. Power generation, in particular, remained within $\sim 5 \%$ of 2019 levels.

Reductions in $\mathrm{NO}_{x}$ emissions were apparent in both in situ (5) and satellite (6) observations of $\mathrm{NO}_{2}$ concentrations due to the short atmospheric lifetime of $\mathrm{NO}_{x}(<1 \mathrm{~d})$. Estimates of $\mathrm{NO}_{x}$ emissions reductions from assimilating satellite data in global models (7), combining global chemical models with machine learning trained on surface measurements (8), or activity data (including electricity use, traffic/mobility data, flight data, etc.) (9-11) find regional reductions of 10 to $40 \%$ during the strictest lockdown periods. Generally, methods assimilating satellite data report smaller reductions (10 to 20\%) than studies based on activity data (25 to $40 \%$ ). Estimates of the reduction in global $\mathrm{NO}_{x}$ emissions in the first half of 2020 range from 5\% (8) to $13 \%$ (7).

The change in global $\mathrm{CO}_{2}$ emissions was comparable to that of $\mathrm{NO}_{x}$ emissions, as seen in Fig. 3. Liu et al. (13) report a peak global reduction of $\sim 15 \%$ (4 $\mathrm{Tg} \mathrm{C}$ or $15 \mathrm{Mt} \mathrm{CO}_{2}$ ) in April and an annual total of 5.4\%. In March 2020, Le Quéré et al. (14) projected a slightly larger $7 \%$ decrease in $\mathrm{CO}_{2}$ over the remainder of 2020. The largest decreases occurred in the first half of 2020, as shown in Fig. $4 A$, and were primarily associated with reductions in ground transportation (15). The response of atmospheric $\mathrm{CO}_{2}$ mixing ratios can be observed near the emissions sources; during the strictest lockdowns, Turner et al. (16) were able to use $\mathrm{CO}_{2}$ observations from a local ground-based network to estimate a $48 \%$ reduction in traffic $\mathrm{CO}_{2}$ emissions in the San Francisco Bay Area. Liu et al. (17) found a $63 \%$ (41 parts per million [ppm]) decrease of the typical on-road $\mathrm{CO}_{2}$ enhancement in Beijing,

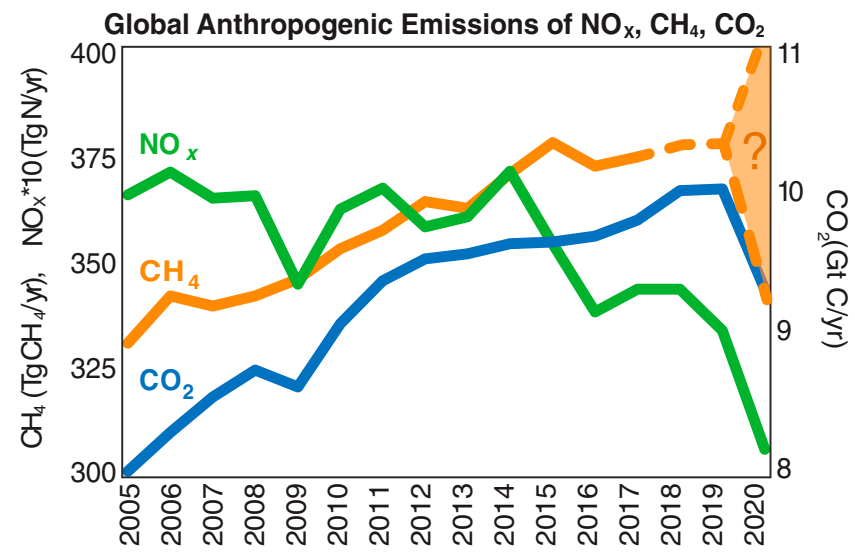

Fig. 3. The year 2020 saw reductions in $\mathrm{CO}_{2}, \mathrm{CH}_{4}$, and $\mathrm{NO}_{x}$ emissions. $\mathrm{CH}_{4}$ and $\mathrm{NO}_{x}$ are plotted along the left axis and $\mathrm{CO}_{2}$ on the right. The dashed line for $\mathrm{CH}_{4}$ after 2017 indicates that it is estimated from the average rate of increase. The 2020 emissions are represented as a range: The IEA estimated a $10 \%$ decrease in $\mathrm{CH}_{4}$ emissions in 2020 (12), but this is uncertain, as the $\mathrm{CH}_{4}$ growth rate increased in 2020. Full details are in SI Appendix. 


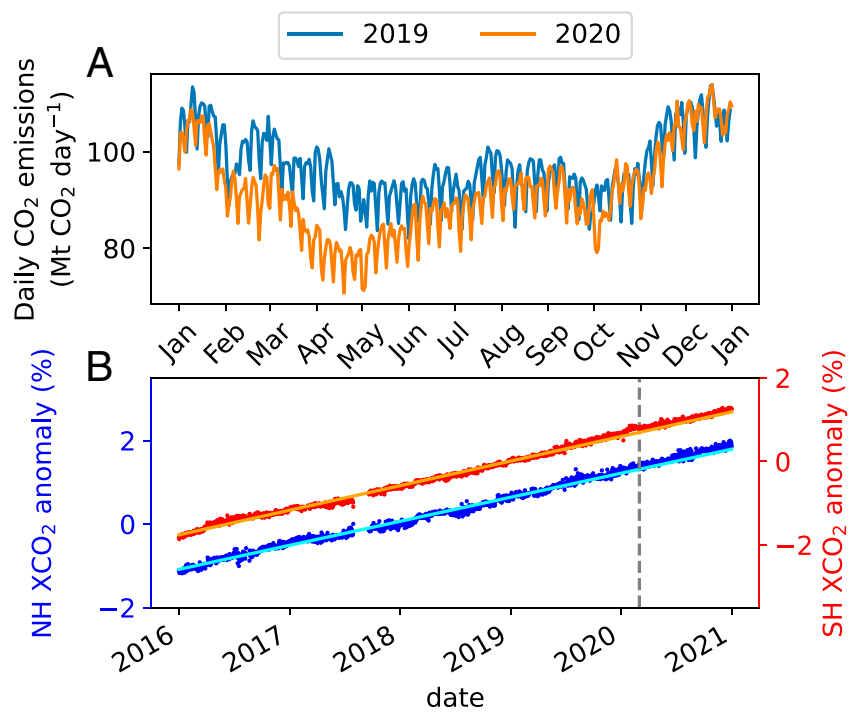

Fig. 4. Despite substantial reductions in anthropogenic $\mathrm{CO}_{2}$ emissions in early 2020, the annual atmospheric $\mathrm{CO}_{2}$ growth rate did not decline. $A$ shows daily global $\mathrm{CO}_{2}$ emissions for 2019 and 2020, calculated following Liu et al. (13). $B$ shows trends in atmospheric column average $\mathrm{CO}_{2}$ from the OCO-2. The small blue and red symbols indicate daily, deseasonalized values as percent anomalies relative to the global 2018 mean. The solid cyan and orange lines are linear fits to 2016-2019 data. In $B$, the vertical gray dashed line marks 1 March 2020 as the approximate beginning of lockdowns in response to COVID-19. A version of $B$ showing the absolute trends and the data including the seasonal cycle is available in SI Appendix, Fig. S8.

China. Distinguishing these signals in $\mathrm{CO}_{2}$ at regional scales is more challenging. Buchwitz et al. (18) infer peak decreases in anthropogenic $\mathrm{CO}_{2}$ emissions from China of $10 \%$ from spacebased total column $\mathrm{CO}_{2}$ measurements. However, they note that the uncertainty is $\sim 100 \%$ and that the expected $\mathrm{CO}_{2}$ concentration signal is 0.1 to $0.2 \mathrm{ppm}$, out of a background of over $400 \mathrm{ppm}$.

Anthropogenic $\mathrm{CH}_{4}$ emissions are dominated by sources such as landfills, oil and gas production, and agricultural activities. The International Energy Agency (IEA) estimates that $\mathrm{CH}_{4}$ emissions dropped by $10 \%$ in 2020 (Fig. 3), largely due to the decrease in demand for oil and gas. However, it is unclear whether reduced demand during 2020 was the primary driver of emissions. It is likely that decreased maintenance of landfills and oil and gas infrastructure during the COVID-19 pandemic led to new leaks in some areas, which can result in those locations becoming $\mathrm{CH}_{4}$ "superemitters" (19). In general, the type, maintenance level, and throughput of $\mathrm{CH}_{4}$ infrastructure can have a large impact on the amount of fugitive emissions $(20,21)$. Further, the downturn in oil and gas prices in 2020 may have resulted in wells being left uncapped when the owning company went bankrupt, increasing fugitive $\mathrm{CH}_{4}$ emissions (22). On a positive note, some of the decrease in emissions estimated by the IEA was associated with the installation of new oil and gas infrastructure and the adoption of new $\mathrm{CH}_{4}$ regulations in a number of countries (12). Such decreases would likely be sustained beyond the pandemic period.

\section{$\mathrm{CO}_{2}$ and $\mathrm{CH}_{4}$ Atmospheric Growth Rates}

The effect of $\mathrm{CO}_{2}$ emissions reductions, especially from ground transport, was clearly apparent in urban-scale observations of atmospheric $\mathrm{CO}_{2}$ mixing ratios $(16,17)$. This does not, however, transfer to global-scale observations. Fig. $4 B$ shows deseasonalized trends in column-average $\mathrm{CO}_{2}$ mixing ratios (referred to as $\mathrm{XCO}_{2}$ ) observed by the Orbiting Carbon Observatory 2 (OCO2) instrument. Despite the reduction in $\mathrm{CO}_{2}$ emissions in 2020 (Fig. $4 A$ ), there is no clear deflection of the observed $\mathrm{XCO}_{2}$ below what would be projected based on previous years' growth rates. We compared the variability in actual atmospheric $\mathrm{CO}_{2}$ growth rates derived from the OCO-2 data with that computed from fossil fuel emissions (SI Appendix, Fig. S8B) and found that the change in atmospheric $\mathrm{CO}_{2}$ growth caused by the COVID19 pandemic is smaller than the natural year-to-year variability. This is expected, because the percent change in the $\mathrm{CO}_{2}$ growth rate, in the absence of feedbacks, will match the percent change in emissions. For a typical growth rate of $2.45 \mathrm{ppm} / \mathrm{y}$ since 2016 (SI Appendix, Fig. S8B and ref. 23), the 5.4\% total reduction in $\mathrm{CO}_{2}$ emissions calculated by Liu et al. (13) equals a $0.13 \mathrm{ppm} / \mathrm{y}$ decrease in the $\mathrm{CO}_{2}$ growth rate for 2020-well within the natural variability observed by OCO-2 (SI Appendix, Fig. S8) and surface networks (23).

Wildfires are one element of the variability in $\mathrm{CO}_{2}$ growth rate. The 2019/2020 Australian wildfires emitted $173 \mathrm{Tg}$ of C (634 Mt of $\mathrm{CO}_{2}$ ) between November 2019 and January 2020, over six times more than Australia's average November to January $\mathrm{CO}_{2}$ emissions for 2001 through 2018 (24). This drove an early increase in $\mathrm{CO}_{2}$ in 2020, evident in the deseasonalized Southern Hemisphere OCO-2 $\mathrm{XCO}_{2}$ (Fig. $4 B$, red series) and growth rate derived from the OCO-2 data (SI Appendix, Fig. S8B). This wildfire anomaly offset a third of the $518 \mathrm{Tg}$ of $\mathrm{C}(1,901 \mathrm{Mt}$ of $\mathrm{CO}_{2}$ ) reduction in anthropogenic $\mathrm{CO}_{2}(13)$ and so does not fully explain the offset between emissions and atmospheric mixing ratios for $\mathrm{CO}_{2}$.

The atmospheric $\mathrm{CO}_{2}$ growth rate led to a reduction in the rate of oceanic $\mathrm{CO}_{2}$ uptake. Fig. 5 shows the magnitude of ocean carbon fluxes over $8 \mathrm{y}$, as computed from a model ensemble under normal and COVID-like emissions. The COVID-like emissions scenario was chosen near the beginning of the pandemic and so had to assume how $\mathrm{CO}_{2}$ emissions would recover. However, it does match the bottom-up emissions shown in Fig. $4 A$ (13) reasonably well through November 2020 (26).

Fig. 5 shows that a reduction from normal to COVID-like emissions results in a decrease in ocean carbon uptake. There is significant variation in the sea-air and $\mathrm{CO}_{2}$ flux among the model ensemble members. This spread represents the potential interannual variability in $\mathrm{CO}_{2}$ flux; given that variability, the true change in $\mathrm{CO}_{2}$ flux in 2020 is uncertain, in part due to corresponding variability in the land carbon sink (SI Appendix, Fig. S9). However, the ensemble mean indicates that while on short time scales, the land carbon flux is insensitive to the change in emissions (SI Appendix, Fig. S9), the ensemble mean ocean uptake was reduced by $70 \mathrm{Tg}$ of $\mathrm{C} / \mathrm{y}$ in 2020 . This would offset $14 \%$ of the $\sim 520 \mathrm{Tg}$ of $\mathrm{C} / \mathrm{y}\left(1,901 \mathrm{Mt}\right.$ of $\left.\mathrm{CO}_{2} / \mathrm{y}\right)$ reduction in anthropogenic $\mathrm{CO}_{2}$ emissions in 2020 (13), further dampening the signal from

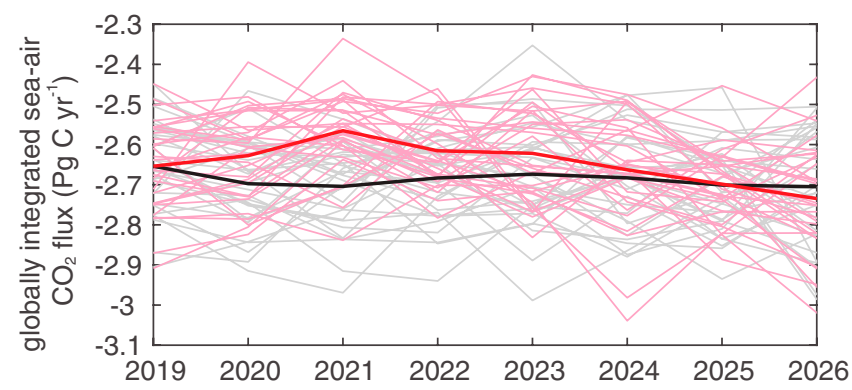

Fig. 5. Sea-air carbon exchange responded quickly to the reduction in anthropogenic $\mathrm{CO}_{2}$ emissions during 2020. Shown here are annual mean, globally integrated sea-to-air carbon dioxide fluxes predicted from the Canadian Earth System Model Version 5-COVID ensemble $(25,26)$. Black/gray lines derive from simulations forced with Shared Socioeconomic Pathways 2-RCP4.5 $\mathrm{CO}_{2}$ emissions, while red/pink lines derive from simulations forced with a $25 \%$ peak $\mathrm{CO}_{2}$ emissions reduction in 2020 . See refs. 25 and 26 for more details. Thick lines are ensemble averages, and thin lines are individual ensemble members, each with different phasing of internal variability. 
emissions reductions in atmospheric $\mathrm{CO}_{2}$. Since real-world $\mathrm{CO}_{2}$ emissions recovered faster than the scenario used in this model ensemble, the actual change in ocean uptake may be smaller.

The growth rate of $\mathrm{CH}_{4}$ was also not slowed by the pandemic. Fig. $6 A$ shows trends in column average $\mathrm{CH}_{4}\left(\mathrm{XCH}_{4}\right)$ from two ground-based spectrometers in the Total Carbon Column Observing Network (TCCON; refs. 27 and 28) located in Park Falls, WI (29), and Lauder, New Zealand $(30,31)$. The $\mathrm{XCH}_{4}$ values after 1 March 2020 lie $~ 0.3 \%$ above the 2016-2019 trend in both hemispheres. Similarly, the National Oceanic and Atmospheric Administration reported the single largest increase in $\mathrm{CH}_{4}$ in its record (32).

Because the lifetime of $\mathrm{CH}_{4}$ depends on the abundance of the hydroxyl radical $(\mathrm{OH})$, the concentration of $\mathrm{CH}_{4}$ varies with atmospheric pollution levels. In fact, we find compelling evidence that the jump in $\mathrm{CH}_{4}$ mixing ratios during 2020 is partly due to reductions in $\mathrm{NO}_{x}$ emissions. In a model incorporating the decreased $\mathrm{NO}_{x}$ emissions associated with COVID-19 (33), the resulting decrease in global ozone (7) leads to a 2 to $4 \%$ decrease in global $\mathrm{OH}$ concentrations. As oxidation by $\mathrm{OH}$ is the primary loss process for atmospheric $\mathrm{CH}_{4}$, this acts to increase $\mathrm{CH}_{4}$ mixing ratios in the atmosphere. Fig. $6 B$ compares the trend in $\mathrm{XCH}_{4}$ measured by TCCON to that predicted by a box model (34). The purple series is the monthly percent difference of TCCON $\mathrm{XCH}_{4}$ from the linear trends shown in Fig. $6 A$, and the gray line is the percent difference between a box model run with and without a $3 \%$ decrease in $\mathrm{OH}$ during 2020. The box model closely matches the extra growth in atmospheric $\mathrm{CH}_{4}$ during 2020 , providing strong evidence that the change in $\mathrm{OH}$ was an important driver of the observed $\mathrm{CH}_{4}$ growth. As $\mathrm{NO}_{x}$ emissions largely recovered by 2021 , we expect that the $\mathrm{CH}_{4}$ growth rate would return to its prepandemic value in 2021 if $\mathrm{OH}$ was the
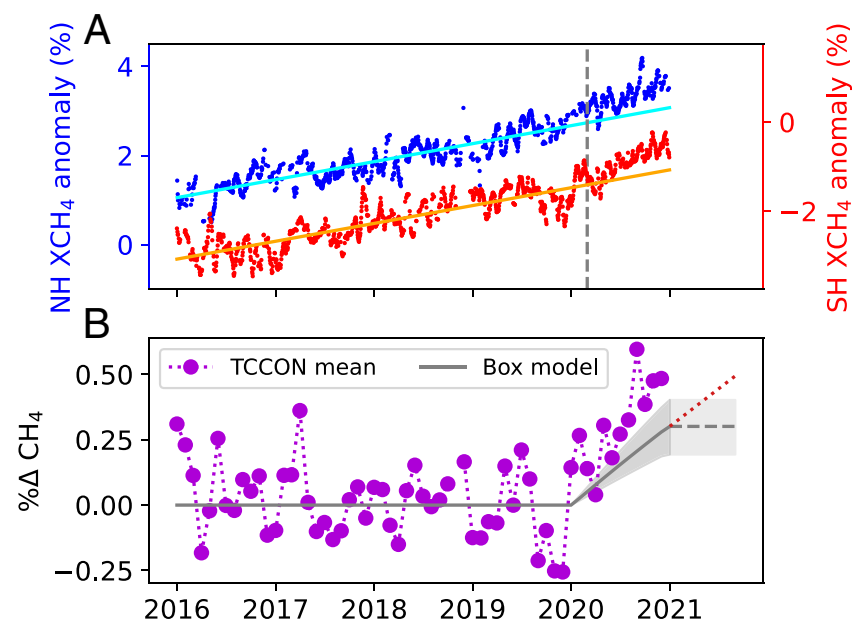

Fig. 6. Atmospheric mixing ratios of $\mathrm{CH}_{4}$ increased more rapidly in 2020 than they had in the past decade. The increase is consistent with no change in $\mathrm{CH}_{4}$ emissions and a $3 \%$ decrease in $\mathrm{OH}$ (predicted from decreased $\mathrm{NO}_{x}$ emissions) during 2020. $A$ is similar to Fig. $4 B$, except that it shows trends in column-average $\mathrm{CH}_{4}\left(\mathrm{XCH}_{4}\right)$ from two TCCON sites: Park Falls, WI, in the Northern Hemisphere (NH) and Lauder, New Zealand, in the Southern Hemisphere $(\mathrm{SH})$ instead of OCO-2 $\mathrm{XCO}_{2}$. $B$ compares the TCCON $\mathrm{XCH}_{4}$ trend to that predicted by a box model. The purple series are the monthly mean percent differences between the TCCON $\mathrm{XCH}_{4}$ and linear fits from $A$. The gray line represents the percent difference in $\mathrm{CH}_{4}$ predicted by a box model (34) with a 3\% decrease in $\mathrm{OH}$ during 2020 compared to no change in $2020 \mathrm{OH}$. The shaded gray area represents the range in modeled $\mathrm{CH}_{4}$ corresponding to the 2 to $4 \%$ range in the $\mathrm{OH}$ anomaly. The values from 2021 on represent possible $\mathrm{CH}_{4}$ growth rates after $\mathrm{NO}_{x}$ emissions recover to prepandemic levels; the dashed gray line represents the behavior if changes in $\mathrm{OH}$ were the governing factor during 2020, while the dotted red line indicates a possible trend if not. dominant factor affecting the 2020 growth rate (dashed gray line, Fig. $6 B)$.

While this supports the hypothesis that changes in $\mathrm{OH}$ altered the growth rate of $\mathrm{CH}_{4}$ in 2020, it does not exclude effects from other sources. Past variability in anthropogenic and natural sources (35) suggests that such variation also played a role in the 2020 growth rate. As discussed above, there is large uncertainty in the trajectory of anthropogenic $\mathrm{CH}_{4}$ emissions during the pandemic. Isotopic measurements of $\mathrm{CH}_{4}$ can help differentiate these changes from natural sources, such as wetlands. However, previous studies $(36,37)$ have shown that changes in the $\mathrm{OH}$ sink can obfuscate changes in $\mathrm{CH}_{4}$ sources if not accounted for; therefore, future studies of $\mathrm{CH}_{4}$ source apportionment through 2020 must account for this likely variation in $\mathrm{OH}$. Finally, as $\mathrm{NO}_{x}$ emissions have generally been restored to prepandemic levels, the impact on the acceleration in $\mathrm{CH}_{4}$ growth should end in 2021, and, thus, absent changes in the emissions of $\mathrm{CH}_{4}$, the growth rate of $\mathrm{CH}_{4}$ should return its prepandemic value in the next few years.

If decreases in anthropogenic $\mathrm{NO}_{x}$ emissions during 2020 were responsible for the increase in $\mathrm{CH}_{4}$ lifetime that led to its higher than expected growth rate, what does this imply for the effect of future efforts to reduce $\mathrm{NO}_{x}$ emissions to improve AQ? To understand this, we need to examine how the $2020 \mathrm{NO}_{x}$ decreases affected $\mathrm{AQ}$ around the world. In the next section, we will describe the ozone and $\mathrm{PM}$ response to these $\mathrm{NO}_{x}$ reductions. Afterward, we will explore the implications of this AQ-GHG feedback in Discussion.

\section{Heterogeneity in AQ Response}

Most parts of the world saw significant decreases in $\mathrm{NO}_{x}$ emissions during the pandemic, but the magnitude and timing of these emissions changes varied with location. Fig. $7 A-C$ compare time series of $\mathrm{NO}_{2}$ column densities measured by the Tropospheric Monitoring Instrument (TROPOMI) for three cities. Following the beginning of lockdown measures (indicated by the dotted lines), the $2020 \mathrm{NO}_{2}$ column densities are clearly less than in 2019. However, in Los Angeles (LA), the drop in $\mathrm{NO}_{2}$ occurred very rapidly when lockdowns were enacted in early March, but by May, there was little difference between 2019 and 2020. In Lima, on the other hand, the difference between 2019 and 2020 grew from March through May. In Shanghai, we see a very large drop in $\mathrm{NO}_{2}$ associated with the early lockdown in January and a smaller drop during the second lockdown in late February.

These changes in $\mathrm{NO}_{x}$ emissions drove changes in secondary pollutants, such as ozone and PM. However, the ozone and PM responses depended on the local chemical regime and meteorology, as well as the magnitude and timing of the $\mathrm{NO}_{x}$ emissions reductions.

In this section, we describe the factors controlling the ozone response first, followed by total and nitrate PM. We selected ozone and nitrate PM as key APs to focus on because both are strongly driven by changes in $\mathrm{NO}_{x}$ emissions. We also compare the modeled change in nitrate PM to the total measured PM.

We recognize that nitrate makes up a modest fraction of total PM compared to other PM types (e.g., organic or sulfate aerosol) (38). For this work, we focus on nitrate PM because it has a less complicated dependence on $\mathrm{NO}_{x}$ emissions (39) than other PM types. We expect that future studies will make use of data collected throughout 2020 to more deeply explore the factors controlling all types of PM.

Ozone. Ozone is a secondary pollutant produced in the atmosphere from the reaction of $\mathrm{NO}_{x}$ and $\mathrm{OH}$ with volatile organic compounds (VOCs). The response of ozone concentrations to changes in $\mathrm{NO}_{x}$ emissions is characterized by the ozone production efficiency (OPE), which is the ratio of the change in ozone for a given change in $\mathrm{NO}_{x}$. 


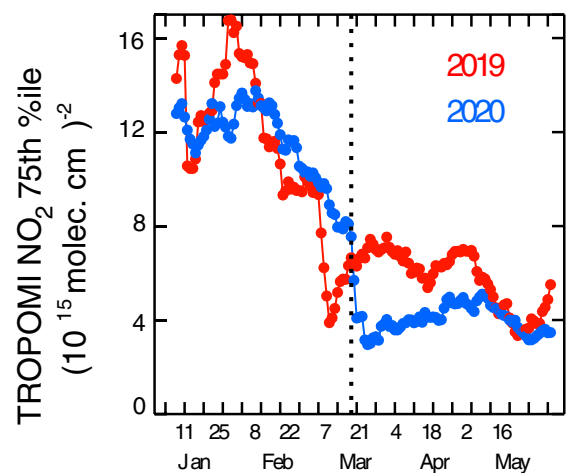

B

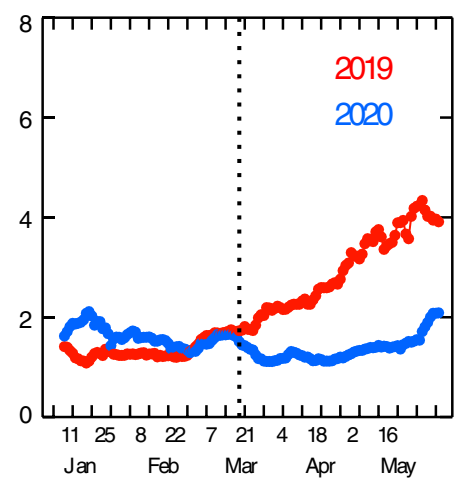

C Shanghai, China

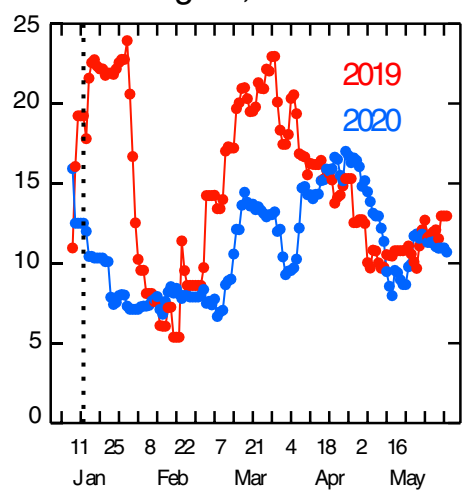

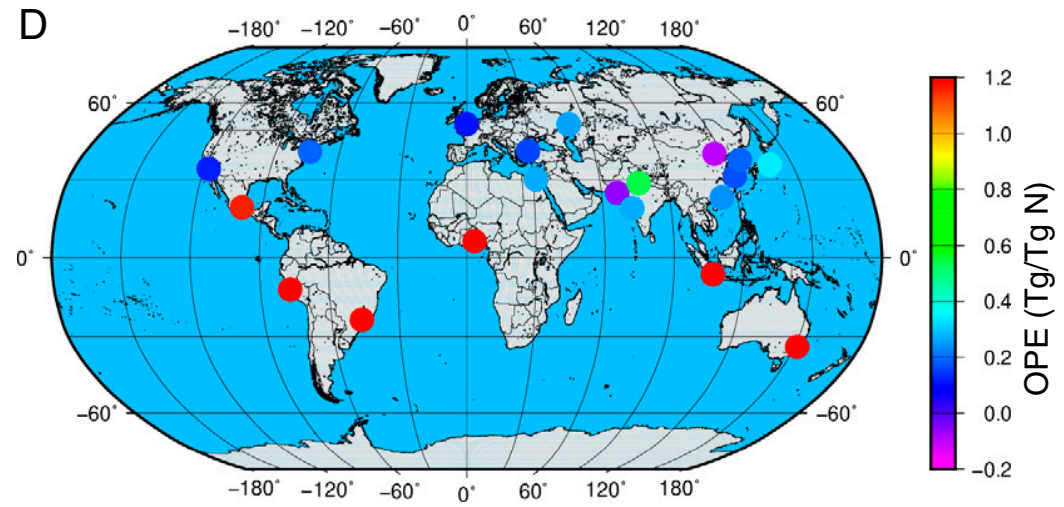

$\mathrm{E}$

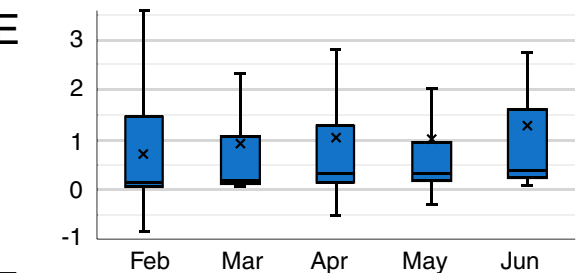

$\mathrm{F}$

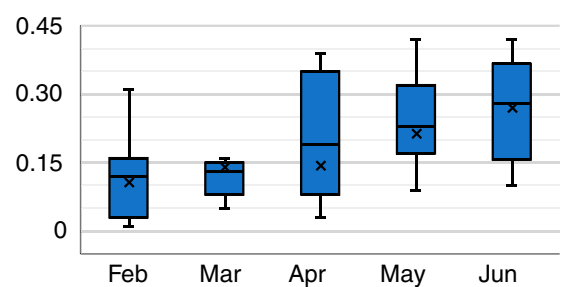

Fig. 7. COVID-19 lockdowns dramatically reduced urban $\mathrm{NO}_{2}$ levels, which, in turn, drove changes in $\mathrm{O}_{3}$ production. $A-C$ show $15-\mathrm{d}$ rolling averages of 75th-percentile (\% ile) TROPOMI NO 2 column densities (molec. = molecules) in three cities for 2019 and 2020 . The vertical dotted line indicates the beginning of lockdown measures in 2020. D shows OPE modeled in 17 megacities, averaged from February to June $2020 . E$ shows modeled monthly global averaged tropospheric OPE. The whiskers are the minimum and maximum, the horizontal lines the quartiles and median, and the $\mathrm{X}$ is the mean. $F$ is similar to $E$, but averaged over $30^{\circ} \mathrm{N}$ to $90^{\circ} \mathrm{N}$.

Accurately modeling the OPE to understand how ozone concentrations will respond to changes in $\mathrm{NO}_{x}$ emissions remains an important challenge in predicting future ozone concentrations. A 2006 model ensemble study reported by Dentener et al. (40) reported $1 \sigma$ SDs of 50 to $80 \%$ in modeled global mean changes of surface ozone between 2000 and 2030. Young et al. (41) showed that net ozone production in 2030 varies by a factor of $\sim 3$ in the Atmospheric Chemistry and Climate Model Intercomparison Project models under the Representative Concentration Pathway (RCP) 4.5 scenario. More recently, Thornhill et al. (42) reported that the response in change of ozone radiative forcing per unit change in lightning $\mathrm{NO}_{x}$ emissions varied by a factor of 2. Providing more accurate constraints on OPE has been challenging due to the lack of direct observations of OPE available to constrain models. Because the change in $\mathrm{NO}_{x}$ emissions during the COVID lockdowns was a large step change, it provides a chance to observe the ozone response to a $\mathrm{NO}_{x}$ perturbation with fewer confounding factors than in a decadal trend. Further, the varied timing of the lockdown-induced $\mathrm{NO}_{x}$ reductions allows us to explore the latitudinal and seasonal variation in OPE.

Fig. $7 D-F$ show OPE calculated in a global model that assimilates multiple satellite measurements. The OPE values shown represent the change in ozone mass burden per unit change in mass of reactive nitrogen emissions, using the COVID-19 reduction in emissions as the $\Delta \mathrm{NO}_{x}$. To avoid convolving meteorological and emissions effects, these OPE values are derived from a pair of model simulations with the same meteorology, but different $\mathrm{NO}_{x}$ emissions (business-as-usual vs. COVID). More detail is given in SI Appendix.
Two patterns in the OPEs demonstrate the significant spatial and temporal variability in the relationship between $\mathrm{NO}_{x}$ emissions and ozone concentrations. First, in Fig. $7 F$, the OPE in the Northern Hemisphere increases between February and June. This is mostly due to increasing sunlight driving key photolysis reactions more rapidly. Thus, the timing of $\mathrm{NO}_{x}$ emissions changes plays a significant role in the magnitude of the ozone response in the midlatitudes and high latitudes, with a smaller ozone response to a given $\mathrm{NO}_{x}$ change during spring than during summer. Second, in Fig. $7 D$, tropical and subtropical cities have the largest, most positive OPEs. Furthermore, there is little change in OPE with season for these cities (Fig. $7 E$ ) due to the relatively small changes in insolation at low latitudes. Fig. $7 D$ indicates that most of the northern midlatitude cities have small, positive OPEs. Two cities, however, have slightly negative OPEs (Beijing, -0.10 ; Karachi, -0.06); a negative OPE indicates that ozone increased when $\mathrm{NO}_{x}$ emissions decreased. Other studies have, in fact, identified large ozone increases in China (43) associated with the decreased $\mathrm{NO}_{x}$ emissions during the pandemic. Additional increases in ozone were observed in Europe (44), with smaller, but still positive, changes in ozone in the United Kingdom (45).

We use a steady-state model (SI Appendix, Fig. S10) to interpret the patterns in Fig. 7. From the steady-state model, we know OPE is small at both low and high $\mathrm{NO}_{x}$ concentrations, but large at intermediate $\mathrm{NO}_{x}$ concentrations. Overall OPE also increases with $\mathrm{VOC}$ reactivity $\left(\mathrm{VOC}_{\mathrm{R}}\right.$, the total rate of reaction of all VOCs with $\mathrm{OH}$ in a given parcel of air) for $\mathrm{NO}_{x}$ concentrations greater than $\sim 0.1$ parts per billion (ppb). Thus, in Fig. 7 , areas with negative OPE are in the high-NO $\mathrm{NO}_{x}$ part of the OPE curve; 
sustained efforts to reduce $\mathrm{NO}_{x}$ emissions will bring them closer to the maximum-OPE tipping point, after which $\mathrm{NO}_{x}$ reductions should lead to ozone reductions. Cities in the tropics and subtropics have large, positive OPE values. This is partly due to plentiful sunlight to drive photochemistry, but these regions also have large $\mathrm{VOC}_{R}$ values due to the abundance of biogenic VOCs (46). The steep dependence of OPE on $\mathrm{NO}_{x}$ follows because $\mathrm{NO}_{x}$ is the limiting reactant in ozone production in these high-VOC $\mathrm{C}_{\mathrm{R}}$ conditions. Thus, these cities should see large ozone reductions from $\mathrm{NO}_{x}$ reductions. However, of the equatorial cities shown in Fig. 6, only those located in South Asia had large enough reductions in $\mathrm{NO}_{x}$ emissions during the COVID-19 pandemic to produce substantial reductions in surface ozone ( 3 to $5 \mathrm{ppb}$ ) (7).

Comparing our OPEs to those from past model studies provides evidence of a long-term transition to $\mathrm{NO}_{x}$-limited chemistry. Fry et al. (47) found mostly negative OPEs with 2001 emissions, while Zhang et al. (48) found positive OPEs with 2010 emissions. Our OPEs are still mostly positive, but typically smaller than those of Zhang et al. This pattern is consistent with moving from $\mathrm{NO}_{x}$-suppressed to $\mathrm{NO}_{x}$-limited chemistry (SI Appendix, Fig. S10). However, we see that there are differences in the sign of OPE among cities in south and east Asia. This indicates that it is important to track local, rather than regional, OPE values to understand the driving chemistry in a given city.

We also see this heterogeneity in ozone response to $\mathrm{NO}_{x}$ emissions reductions at the intraurban scale. Measurements of daily maximum (DM) $\mathrm{NO}_{2}$ and ozone at monitoring sites throughout the LA Basin show consistent reductions in $\mathrm{NO}_{2}$ throughout the basin in March and April of 2020, but smaller reductions in ozone in the central northern part of the basin than elsewhere (SI Appendix, Figs. S1 and S2). This is consistent with the nearzero OPE for LA in Fig. $7 D$, i.e., for a city on the verge of reducing $\mathrm{NO}_{x}$ emissions to the point where $\mathrm{NO}_{x}$ is the limiting factor in ozone production. While the overall basin chemistry is at this tipping point, local differences in emissions as well as transport of pollutants within the basin can lead to these smallscale differences in ozone response (49).

However, the behavior of ozone in the LA Basin also illustrates that ozone production depends on temperature; thus, $\mathrm{NO}_{x}$ controls may become less effective in a warmer climate. Fig. 8 , Top and Middle show time series of $\mathrm{DM} \mathrm{NO}_{2}$ and ozone. $\mathrm{NO}_{2}$ and ozone concentrations are clearly lower in March and April 2020 compared to the 2015-2019 average, in part due to the reduction in $\mathrm{NO}_{x}$ emissions at the beginning of the lockdown. However, these 2 months were significantly cooler than the 20152019 average as well. When temperatures rose above average during an unusual heat wave in late April and May of 2020, ozone DM rose above the range seen in 2015-2019, despite the fact that $\mathrm{NO}_{2}$ remained similar to 2015-2019 concentrations. An increase in ozone during April and May was also seen in a previous study (50). The response of ozone per degree increase in temperature is shown in SI Appendix, Fig. S3. Typical values for the $\mathrm{O}_{3}$ season (May-September) in 2020 throughout the basin were 1.8 to $5.8 \mathrm{ppb} \cdot \mathrm{K}^{-1}$. This is higher than a previous prediction of about $1 \mathrm{ppb} \cdot \mathrm{K}^{-1}$ in the basin (51), suggesting that the ozone climate penalty may be stronger than expected; however, analysis is ongoing.

PM. Achieving long-term reductions in PM (especially PM 2.5, particles with a diameter $<2.5 \mu \mathrm{m}$ ) concentrations is a matter of great importance due to the large health impacts of PM compared to ozone (52). Our interest here is to use observations from the pandemic period to better understand some of the factors controlling atmospheric PM concentrations, rather than focusing on the question of whether PM exposure increases the chance of death from COVID-19.

The factors controlling PM concentration are more complicated than those for ozone. PM arises from primary emissions

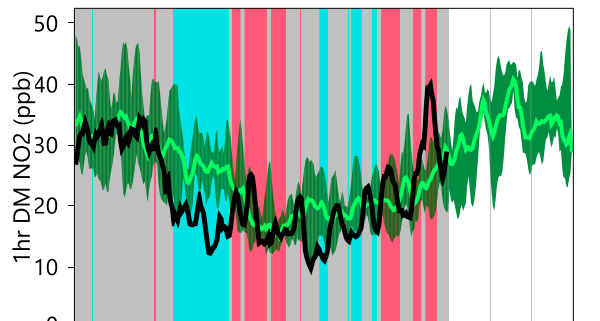

\section{Air Quality \\ 2020 \\ Average [2015-2019]}

Range [2015-2019]

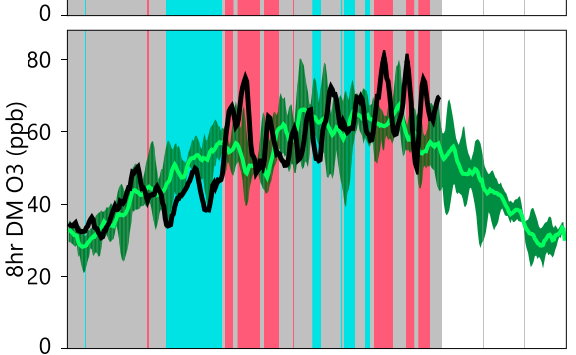

Temperature

Average [2015-2019]

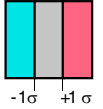

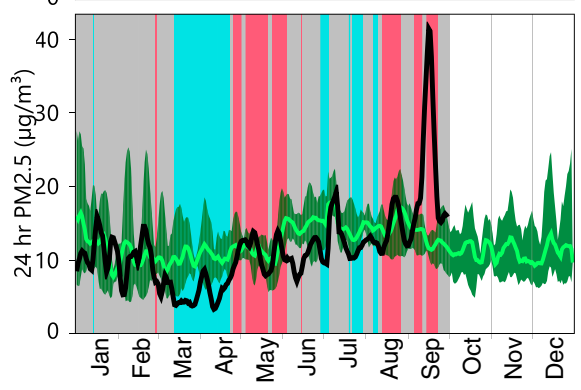

Fig. 8. In LA, temperature and wildfires drove ozone and PM pollution, respectively, more than changes in traffic. The three panels show 7-d rolling average of 24-h $\mathrm{PM}_{2.5}$, 1-h $\mathrm{DM} \mathrm{NO}_{2}$, and 8-h $\mathrm{DM} \mathrm{O}_{3}$, respectively, by day of year in 2020 and in the past 5 y (2015-2019) in the LA Basin. Bars in the background show the 7-d rolling average of basin-average 1-h DM temperature in 2020 relative to the 2015-2019 average $( \pm 1 \sigma)$ by day of year. The 2020 data are preliminary, unvalidated, and subject to change.

and natural sources, as well as secondary chemistry in the atmosphere. One such secondary pathway is the formation of nitrate PM from the reaction of higher oxides of nitrogen (such as $\mathrm{HNO}_{3}$ ) with ammonia (39). Nitrate PM formation via this pathway may be limited by either available $\mathrm{NO}_{x}$ or ammonia.

We use model simulations (SI Appendix, Fig. S4) to evaluate the effect that $\mathrm{NO}_{x}$ emissions reductions had on nitrate PM formation in LA. As with ozone, these results are derived from two model runs with the same meteorology, but different emissions, to isolate changes in chemistry from meteorological effects. Under COVID-19 emissions, the nitrate PM concentrations decreased by $\sim 60 \%$ in April 2020 . At the same time, the model reported a shift toward $\mathrm{NO}_{x}$-limited (rather than ammonialimited) chemistry. This implies that the $\mathrm{NO}_{x}$ emission decreases in April, when the shift in the chemical regime showed the largest change, were more efficient at reducing nitrate than the reductions in other months. Compared to the measured total PM reductions shown in Fig. 8, Bottom, our results suggest that $\mathrm{NO}_{x}$ emissions reductions account for about $10 \%$ of the total $\mathrm{PM}$ reduction in the LA Basin during the COVID-19 lockdowns. This agrees with other recent work (53), which indicates that traffic $\mathrm{NO}_{x}$ emissions contribute less than $10 \%$ of secondary PM production throughout North America, Europe, and East Asia. This is also consistent with the long-term trend in nitrate PM reported by Hasheminassab et al. (54), who showed reasonably consistent decreases of nitrate PM mass in LA between 2002 and 2013. Our work does show a stronger effect of $\mathrm{NO}_{x}$ emissions reductions on nitrate PM than Pusede et al. (55) predicted; 
however, that work focuses on winter nitrate in the San Joaquin Valley, CA, whereas our results focus on springtime PM in LA.

The relative availability of $\mathrm{NO}_{x}$ and ammonia elsewhere in the United States plays an important role in whether $\mathrm{NO}_{x}$ emissions reductions lead to reduced nitrate PM. Simulations of nitrate chemistry over the continental United States show that LA is somewhat unique as an urban area that experienced a significant shift to $\mathrm{NO}_{x}$-limited nitrate chemistry. Other urban areas in the northeast, southeast, and northwest largely remained ammonialimited (SI Appendix, Figs. S5-S7). This could explain, at least in part, the scattered response of $\mathrm{PM}$ to $\mathrm{NO}_{x}$ emissions reductions across US cities seen in other studies (56) and is consistent with weak trend of nitrate PM mass in New York reported by Squizzato et al. (57). Our work also implies that continuing the long-running trajectory of $\mathrm{NO}_{x}$ emissions reductions in LA in order to reach the tipping point where ozone becomes $\mathrm{NO}_{x}$ limited will also benefit $\mathrm{AQ}$ via reduced production of nitrate PM.

However, LA also represents a cautionary tale about attributing AQ changes to the COVID-19 pandemic without accounting for other confounding factors. Weather and wildfires also played a large role in determining the PM concentrations in LA during 2020. When the lockdowns were first instituted in March, news outlets and social media attributed the clean air in the LA Basin to the lack of traffic. However, as seen in Fig. 8, the lower PM concentrations in March and April 2020 than 2015-2019 (Fig. 8, Bottom) coincide with anomalously cool weather, which was accompanied by higher than average precipitation (figure S1 in ref. 49). Precipitation removes PM from the atmosphere through wet deposition $(58,59)$ and was at least partially responsible for the clean air during this period. The extreme spike in PM concentrations seen in September 2020, on the other hand, coincides with a time period when major wildfires were burning in close proximity to LA. Like the April-May heat wave, this event also points to the fact that climate change can erase existing progress in AQ improvements.

\section{Discussion}

The changes in atmospheric composition throughout 2020 unequivocally demonstrate that $\mathrm{AQ}$ and GHGs cannot be treated as separate problems, despite the disparate time scales of AQ and GHG responses to changes in human activity. AQ is most dependent on local changes in emissions because of the shorter atmospheric lifetime and rapid chemistry of APs. In contrast, the global total GHG emissions matter more than local emissions, as it is the overall GHG atmospheric growth rate that drives climate change. As discussed above, improvements in AQ made by reducing pollutant emissions locally can be offset by changes in meteorology or nonanthropogenic (e.g., biogenic or wildfire) emissions driven by climate change. Likewise, changes in AQ can alter the radiative forcing driving climate change, as decreases in AP emissions could lead to increased lifetimes for shorter-lived GHGs (such as $\mathrm{CH}_{4}$ ), increasing their global warming potential.

Reductions in $\mathrm{NO}_{x}$ emissions during the pandemic did show the potential benefits cities can gain by promoting systemic change to accomplish these same reductions. For most countries, the pandemic-induced emissions reductions can be seen as going back in time to a period when $\mathrm{NO}_{x}$ emissions were lower. In the United States, Europe, and China, where $\mathrm{NO}_{x}$ emissions have been trending downward, these reductions were more akin to a jump forward in time to a lower-emissions future. Fig. 9 shows the equivalent year for each country's $\mathrm{NO}_{x}$ emissions during the pandemic, assuming recent trends in $\mathrm{NO}_{x}$ emissions hold constant. Most striking is how much more quickly China could reach pandemic-like emissions levels than the United States or Europe. Though all three regions' emissions reductions had similar peak magnitudes (18 to 20\%), Europe and especially the United States are further along their respective

\section{COVID-19 Equivalent $\mathrm{NO}_{x}$ Emissions Year by Country}

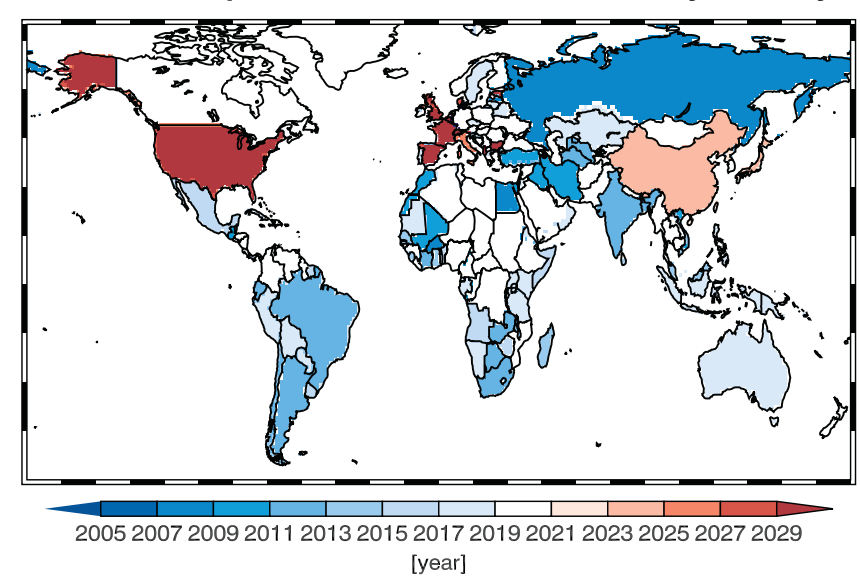

Fig. 9. The emissions reductions during the pandemic are, in a sense, like moving forward or back in time. Countries are colored by the year to which their $2020 \mathrm{NO}_{x}$ emissions are equivalent, projected forward in time where emissions have been decreasing and backward elsewhere. Details of emissions estimates are given in SI Appendix.

$\mathrm{NO}_{x}$-reduction pathways than China. This, combined with China's higher prepandemic emissions levels, means that China can make progress quickly if they are able to maintain the aggressive pace of emissions reductions they have set over the past decade (33).

Many cities in the United States and Europe are close to reaching a point at which $\mathrm{NO}_{x}$ emissions will be a very effective control on ozone concentrations. In Fig. $7 D$, cities with an OPE near zero are likely at the tipping point between VOC-limited and $\mathrm{NO}_{x}$ limited chemistry. Further $\mathrm{NO}_{x}$ reductions should move them firmly into $\mathrm{NO}_{x}$-limited chemistry, where $\mathrm{NO}_{x}$ is the primary control on ozone formation. While sustaining these emissions reductions may be challenging due to the decreasing contribution of on-road gasoline emissions (60) and the impact of emissions reductions being offset in part by increases in chemical lifetime (61), the rewards in doing so are likely substantial. In addition, since $\mathrm{NO}_{x}$ and $\mathrm{CO}_{2}$ are coemitted by combustion processes, regulations such as those that encourage a transition to electric vehicles will also reduce GHG emissions driving climate change. In fact, recent work has shown that the cost savings associated with reduced health impacts from air pollution will outweigh the cost of transition to a clean carbon economy and that the increased radiative forcing from longer-lived $\mathrm{CH}_{4}$ and ozone is balanced by the decrease in forcing from smaller $\mathrm{CO}_{2}$ mixing ratios (62). On the other hand, measures such as $\mathrm{NO}_{x}$ removal from coal-fired power plants will benefit AQ, but not limit GHG emissions and, thus, their impact on climate change; as discussed below, this will eventually limit their effectiveness for improving AQ.

The same strategies to improve AQ will not be equally effective in all locations. On one hand, the tropical and subtropical cities with large, positive OPE values in Fig. $7 D$ can immediately realize substantial ozone reductions through reductions in $\mathrm{NO}_{x}$ emissions. On the other hand, cities such as Beijing and Karachi with negative OPEs or locations such as the United Kingdom, where in situ studies found a negative correlation between $\mathrm{NO}_{x}$ emissions and ozone concentrations (45), would do better to reduce VOC reactivity simultaneously with $\mathrm{NO}_{x}$ emissions. Such an approach would allow them to avoid the chemical regimes with the largest OPEs (63) (SI Appendix, Fig. S10A). Similarly, while chemical formation of ammonium nitrate PM in LA became $\mathrm{NO}_{x}$-limited during the pandemic, most other cities in the United States remain ammonia-limited and would see stronger reductions in PM by controlling primary emissions, organic precursors, or other key species. 
Unfortunately, 2020 has also shown that improvements in AQ are likely to be offset by climate feedbacks. Such effects were most apparent in LA, where warmer than average May temperatures led to ozone concentrations above the 2015-2019 average; greater than average precipitation in March and April likely contributed to the reduction in PM; and severe wildfires from late August through September caused PM concentrations four times that of the 2015-2019 average. Changing climate will affect each of these variables, leading to warmer temperatures, more wildfires (64), and potentially more intense, but less frequent, precipitation (65), giving PM more time to accumulate between wet deposition events.

Changes in AP emissions, particularly $\mathrm{NO}_{x}$ emissions, have potential to feed back into climate change as well. As we showed in Fig. 6, there is compelling evidence that reductions in $\mathrm{OH}$ stemming from reduced anthropogenic $\mathrm{NO}_{x}$ emissions drove a $\sim 0.3 \%$ jump in $\mathrm{CH}_{4}$ during 2020. While tropical cities have the greatest potential for decreasing ozone by reducing $\mathrm{NO}_{x}$ emissions (Fig. 7D), they also have an outsized impact on atmospheric $\mathrm{CH}_{4}$ lifetime, as the largest share of $\mathrm{CH}_{4}$ oxidation occurs in the tropics (34). Since only tropical cities in South Asia had substantial changes in $\mathrm{NO}_{x}$ emissions during 2020 (7), 2020 represents a minimum benchmark for the effect of $\mathrm{NO}_{x}$ reductions on the $\mathrm{CH}_{4}$ growth rate. It is therefore essential to invest in strategies to reduce fugitive $\mathrm{CH}_{4}$ emissions (such as updated $\mathrm{CH}_{4}$ storage and transportation infrastructure to prevent and limit leaks, landfill $\mathrm{CH}_{4}$ capture, and confined animal feed-operation $\mathrm{CH}_{4}$ mitigation) ahead of decreases in tropical $\mathrm{NO}_{x}$ emissions.

In terms of GHG emissions driving climate change, despite a reduction in global emissions equivalent to going back in time $9 \mathrm{y}$ (to 2011-equivalent $\mathrm{CO}_{2}$ emissions), any change to the global $\mathrm{CO}_{2}$ growth rate was smaller than typical interannual variability. As mentioned earlier and discussed in more detail below, this is partly due to the offsetting reduction in ocean carbon uptake (Fig. 5), but also arises because the sharp decreases in $\mathrm{CO}_{2}$ emissions during the first half of 2020 were not sustained. By the second half of 2020, emissions due to power generation, industry, and residential consumption had nearly returned to 2019 levels (13). If we assume that these emissions levels represent a balance between reduced activity to limit the spread of COVID-19 and sufficient activity to maintain a minimum economic productivity, this suggests that reducing activity in these sectors is not practical. Reducing these sectors' emissions permanently will require their transition to low-carbon-emitting technologies.

One interesting aspect of the GHG emissions reductions during the pandemic was that they provided a chance to study the feedback in ocean carbon uptake. The model simulations using COVID-like $\mathrm{CO}_{2}$ emissions shown in Fig. 5 indicate that the seaair carbon flux adjusts rapidly in response to changes in anthropogenic emissions. That model ensemble mean indicates a response time of about $1 \mathrm{y}$. Although this basic response-a decline of the ocean carbon sink in response to mitigation-is accounted for in the RCP scenarios (66), much uncertainty remains as to the accuracy of these ocean sink predictions. This uncertainty is due both to the forced response of the ocean and to interannual variability. Lovenduski et al. (26) found that, for a change in ocean carbon uptake to be observable with our current network of ocean buoy measurements, it would need to be four times larger than the COVID-19 emissions reductions. This will be a challenge as we work to quantify the effect of future permanent $\mathrm{CO}_{2}$ emissions reductions on atmospheric $\mathrm{CO}_{2}$ mixing ratios.

The pandemic does offer insight into how the atmospheric GHG growth rates could be curtailed: systemic changes are required to enable sustained reductions in emissions. The efficacy of sustained reductions (without systemic changes to the energy sector) can be seen in the contrast between $\mathrm{CO}_{2}$ emissions from ground transport and international shipping and aviation ("international bunkers") reported by Liu et al. (13) The peak reduction in international bunkers' emissions was only $\sim 1 / 3$ that of the reduction in emissions from ground transport, by mass. However, while ground transport recovered fairly quickly, the international bunkers' emissions remained at about half of 2019 levels throughout the second half of 2020. As a result, the cumulative reduction in 2020 emissions due to international bunkers was $75 \%$ that of the reduction due to traffic, despite the comparatively small magnitude of the daily emissions from international bunkers.

Sustained reduction in other sectors will require investment in renewable energy and new technologies to support current levels of productivity with lower carbon emissions-that is, to reduce the carbon intensity of our economy. Such investment is essential, as several studies $(67,68)$ have documented the harm to employment, family connections, and other critical human connections from the reduction in personal mobility due to the pandemic. Liu et al. (13) note that Spain's 2020 emissions due to power generation were almost $25 \%$ lower than in 2019 due to investment in renewable energy. A post-COVID economic recovery represents an opportunity to invest in carbon-reducing technologies (69), as long as the need to balance short-term job creation with long-term retraining is accounted for (70). If this investment was able to continue the trend of a $5.4 \%$ decrease in global $\mathrm{CO}_{2}$ emissions per year, we would reach "preindustrial" (circa 1850) emissions levels in $\sim 18 \mathrm{y}$.

\section{Strengths and Weaknesses of Current Observing Systems}

Understanding how the COVID-19 pandemic has altered AQ and the carbon cycle has relied heavily on the multifaceted observing system built over the past two decades, including satellites, dense ground-based observing networks, Earth system and chemical transport models, and techniques to assimilate observations into these models. Novel data on human activity (particularly internet-of-things mobility data, crowd-sourced air traffic data, and even news reports) have also played a vital role in both understanding how human behavior changed during the pandemic and quantifying the effect of that change on anthropogenic emissions.

Nevertheless, there remain important gaps in our observing network. First, space-based detection of VOCs remains a challenging problem, yet quantitative measurements of key biogenic (e.g., isoprene, terpenes) and anthropogenic (e.g., ethene, propene) contributors to $\mathrm{VOC} \mathrm{OH}$ reactivity are needed to identify the dominant chemistry governing $\mathrm{AQ}$ around the globe. Second, as we saw in the LA Basin case study, disentangling primary PM emission, secondary PM formation, and meteorological drivers of PM concentration is crucial to understanding which processes control PM exposure. Given the serious health impacts of PM exposure, work toward integrated analyses of surface and space-based systems that can differentiate these processes is needed to elucidate the optimum approaches to reducing PM exposure.

In regard to climate-change-relevant $\mathrm{GHG}$ observations, spatiotemporally broader and denser space-based GHG observations would provide a highly valuable empirical constraint on changes to anthropogenic and biogenic carbon fluxes. A satellite instrument that provided comparable observations to the $\mathrm{BEACO}_{2} \mathrm{~N}$ network (Berkeley Environmental Air-quality and $\mathrm{CO}_{2}$ Network) in the San Francisco Bay area $(\sim 2-\mathrm{km}$ resolution, strong sensitivity to the near-surface atmosphere, and urban-scale coverage) could apply similar inversion techniques as Turner et al. (16) to infer key sectors' emissions in cities around the world. It is also clear that our current network of near-real-time ocean carbon uptake measurements is not sufficient to disentangle internal variability in the air-sea carbon flux from changes driven by reductions in anthropogenic emissions (26). Expanding this network or developing new methods to constrain the air-sea carbon flux from space will be necessary 
to quantify the impact of anthropogenic emissions reductions on atmospheric $\mathrm{CO}_{2}$ mixing ratios.

\section{Conclusions}

The COVID-19 pandemic and associated changes in human behavior represent an unprecedented rapid change in anthropogenic emissions to the atmosphere. Due to the large differences in relevant atmospheric lifetimes for constituents central to $\mathrm{AQ}$ and climate change, clear changes in local $\mathrm{AQ}$, but not global $\mathrm{GHG}$, trajectories were observed. The response of $\mathrm{O}_{3}$ to the reduction in $\mathrm{NO}_{x}$ emissions (OPE) varied significantly in space and time. Likewise, the reduction in $\mathrm{NO}_{x}$ emissions reduced nitrate PM in LA, but had limited effect elsewhere in the United States. These results indicate that optimum strategies to improve near-future AQ differ around the world. Additionally, changes in $\mathrm{AQ}$ in the LA Basin correlated with temperature, precipitation, and severe wildfires, indicating that shifts in these quantities associated with climate change will at least partially offset gains in AQ made from past and future reductions in anthropogenic emissions. In the long-term, shifting toward electrified transport and renewable electricity generation offers cobenefits to climate and $\mathrm{AQ}$, as discussed above.

Despite large disruptions in transportation-emissions sectors, the global-scale change in the $\mathrm{CO}_{2}$ growth rate was less than interannual variability. This is due to a combination of reduced ocean uptake of $\mathrm{CO}_{2}$, a recovery of $\mathrm{CO}_{2}$ emissions in the second half of 2020, and large interannual variability in land carbon fluxes. The lack of change in $\mathrm{CO}_{2}$ growth rates though 2020 indicates that expecting changes to individual behavior to be sufficient to halt the increase of GHGs in the atmosphere is unrealistic. Instead, incentives to deploy new methods to systematically and sustainably reduce carbon intensity are needed. Given the bidirectional feedback between climate change and $\mathrm{AQ}$, it is clear that climate and AQ can no longer be considered separate problems; prompt action to reduce anthropogenic carbon emissions is essential, not only to avert direct climate change impacts, but to avoid giving up decades of hard-won progress in improving urban AQ.

The COVID-19 experience allowed us to observe the response of Earth system processes to a rapid and large change in human activity, emissions, and consequent impacts. This is in contrast to previous analyses that have had to rely on sophisticated techniques to disentangle long-term anthropogenic signals that are often much smaller than the various uncertainties and natural variability in the system. In addition to geophysical relationships, the pandemic and associated lockdowns also revealed the response of emissions to changes in human behavior and activity, particularly related to mobility and their attendant impacts, which usually have to be inferred far more indirectly. These factors, coupled with the unprecedented observing systems in place during the pandemic, greatly reduce the uncertainties associated with our analysis. For example, Fig. 4 shows the consequences, or lack thereof, of reduced emissions on concentrations of $\mathrm{CO}_{2}$, revealing a critical feedback. Similarly, changes to OPE (Fig. 7) show that the response of ozone to $\mathrm{NO}_{x}$ emissions varies substantially in time and space. The COVID-19 period generated Earth system responses of unusual magnitude, revealing processes with unique clarity, in some cases confirming theory and models, while in others showing unexpected behavior.

\section{Materials and Methods}

Full methods are available in SI Appendix. Analysis of LA Basin AQ used data from California Air Resources Board monitors, filtered for complete

1. T. Hale et al., Oxford COVID-19 government response tracker (Blavatnik School of Government, Oxford, UK, 2020; https://www.bsg.ox.ac.uk/research/researchprojects/covid-19-government-response-tracker). Accessed 20 February 2021.

2. M. Strohmeier, X. Olive, J. Lübbe, M. Schäfer, V. Lenders, Crowdsourced air traffic data from the OpenSky network 2019-20. Earth Syst. Sci. Data 13, 357-366 (2021) data records in the 2015-2020 period. The 1-h DM NO 2 and temperature 8-h $\mathrm{DM} \mathrm{O}_{3}$, and 24-h average PM were calculated from these data. OPE was derived from model simulations using multiconstituent assimilation of multiple satellite measurements in the MIROC-CHASER (Model for Interdisciplinary Research on Climate coupled with the Chemical Atmospheric General Circulation Model for Study of Atmospheric Environment and Radiative Forcing) model (33). OPE was calculated by comparing modeled $\mathrm{O}_{3}$ production and $\mathrm{NO}_{x}$ emission difference between baseline (2010-2019) and reduced 2020 emissions. Separate $\mathrm{PM}_{2.5}$ simulations used Goddard Earth Observing System (GEOS)-Chem version 9-02 with $\mathrm{NO}_{x}$ emissions consistent with the OPE simulations: Baseline $\mathrm{NO}_{x}$ emissions used HTAP v2 scaled to 2017 using satellite-derived emissions-reduction ratios, and COVID NO emissions were scaled down by the same factor as in the OPE simulations. Uncertainty on simulated nitrate PM2.5 was estimated at $54 \%$ from the quadrature sum of errors due to aerosol thermodynamics, $\mathrm{NH}_{3}$ flux scheme, and $\mathrm{NH}_{3}$ emissions. The TROPOMI time-series analysis first regridded native TROPOMI pixels to a $0.01^{\circ} \times 0.01^{\circ}$ grid and filtered to primarily remove cloud and snow/ice-contaminated scenes. The time series show the 75th percentile of $15-\mathrm{d}$ rolling average $\mathrm{NO}_{2}$ columns in a $1^{\circ} \times 1^{\circ}$ box around each city.

Global $\mathrm{CO}_{2}$ emissions estimates were derived from an array of near-realtime data on power generation, industry, transport, and fuel consumption $\mathrm{XCO}_{2}$ growth rates were derived from OCO-2 v10 ocean glint data and $\mathrm{XCH}_{4}$ growth rates from TCCON GGG2014 data. The data shown are 15-d running averages deseasonalized by fitting a four-harmonic curve. Expected $\mathrm{CH}_{4}$ trends were computed from a two-box model (representing the two hemispheres) using prescribed $\mathrm{OH}$ concentrations and constant $\mathrm{CH}_{4}$ emissions after 2012. TCCON data can be obtained from the TCCON Data Archive hosted by CaltechDATA (https://tccondata.org/).

Ocean $\mathrm{CO}_{2}$ flux simulations are from a 30 -member model ensemble $(25$, 26). Differences in ensemble mean fluxes are considered significant at twice the SEM.

Data Availability. GEOS-Chem Model Output data have been deposited in Zenodo (https://zenodo.org/record/4849416) (71). Publicly available datasets are listed along with data generated from this study and stored in publicfacing repositories in SI Appendix, Table S1. Emissions data for Figs. 3 and 9 are given in SI Appendix, Table S2. Data for the OPE values in Fig. 7 are given in SI Appendix, Table S4. Emissions and OPE data are also included as Datasets S1 and S2. In addition, previously published data $(1,2,13,25,29-31$, $35,72-84$ ) were used for this work.

ACKNOWLEDGMENTS. We thank the Keck Institute for Space Studies for organizing and supporting the study "COVID-19: Identifying Unique Oppor tunities for Earth System Science" that led to the writing of this manuscript. We also acknowledge the use of data from the Port of Oakland and Por of LA website, Apple mobility data, and US EIA electricity-use data. We also thank Charles Carter for his artwork in Fig. 1. We thank the TCCON science team for their effort in providing data. Support for operation of the Park Falls TCCON site is provided by NASA. The Lauder TCCON programme is funded by NIWA (National Institute of Water \& Atmospheric Research Ltd.) through Aotearoa New Zealand's Ministry of Business, Innovation and Employment's Strategic Science Investment Fund. The views expressed in this manuscript are solely those of the authors and do not necessarily reflect those of the South Coast Air Quality Management District. A portion of this research was carried out at the Jet Propulsion Laboratory (JPL) California Institute of Technology, under a contract with NASA. This work was supported by NASA Grant NNX17AE15G (to J.L.L. and P.O.W.), NASA Carbon Monitoring System Grant 80NSSC20K0006 (to A.C.), NASA Grant 80 NSSC18K0689 (to D.K.H. and H.C.), NASA Aura Science Team Program 19-AURAST19-0044 (to K.M. and K.W.B.), NASA Grant 80NSSC20K1122 (to D.L.G. and S.A.), NASA Grant 80NSSC21K0508 (to R.V.M.), NSF RAPID Grant 2030049 (to K.B.), NSF Grants OCE-1752724 and OCE-1948664 (to N.S.L.), and NSF Grant OCE-1948624 (to G.A.M.). A.J.T. was supported as a Miller Fellow with the Miller Institute for Basic Research in Science at the University of California Berkeley. K.R.G. was supported by Northern Arizona University startup funds. C.E.I. was supported by the University of California Institute of Transportation Studies. S.P.S. and Z.-C.Z. were supported by the California Air Resources Board, NASA Science Mission Directorate/Earth Science Division, and JPL Earth Science and Technology Directorate. Y.L.Y. was supported in part by JPL OCO-2 Grant JPL.1613918 (to the California Institute of Technology). J.L. was supported by the NASA OCO science team program.

3. M. Schäfer, M. Strohmeier, V. Lenders, I. Martinovic, M. Wilhelm, "Bringing up OpenSky: A large-scale ADS-B sensor network for research" in Proceedings of the 13th IEEEIACM International Symposium on Information Processing in Sensor Networks (IPSN) (IEEE, Piscataway, NJ, 2014), pp. 83-94.

4. X. Olive, Traffic, a toolbox for processing and analysing air traffic data. J. Open Source Softw. 4, 1518 (2019) 
5. C. Lamprecht, M. Graus, M. Striednig, M. Stichaner, T. Karl, Decoupling of urban $\mathrm{CO}_{2}$ and air pollutant emission reductions during the European SARS-CoV-2 lockdown. Atmos. Chem. Phys. 21, 3091-3102 (2021).

6. D. L. Goldberg et al., Disentangling the impact of the COVID-19 lockdowns on urban $\mathrm{NO}_{2}$ from natural variability. Geophys. Res. Lett. 47, e2020GL089269 (2020).

7. K. Miyazaki et al., Global tropospheric ozone responses to reduced $\mathrm{NO}_{x}$ emissions linked to the COVID-19 worldwide lockdowns. Sci. Adv. 7, eabf7460 (2021).

8. C. A. Keller et al., Global impact of COVID-19 restrictions on the surface concentrations of nitrogen dioxide and ozone. Atmos. Chem. Phys. 21, 3555-3592 (2021).

9. J. Xing et al., Quantifying the emission changes and associated air quality impacts during the COVID-19 pandemic on the North China Plain: A response modeling study. Atmos. Chem. Phys. 20, 14347-14359 (2020).

10. M. Guevara et al., Time-resolved emission reductions for atmospheric chemistry modelling in Europe during the COVID-19 lockdowns. Atmos. Chem. Phys. 21, 773797 (2021).

11. T. Doumbia et al., Changes in global air pollutant emissions during the COVID-19 pandemic: A dataset for atmospheric chemistry modeling. Earth Syst. Sci. Data 13, 4191-4206 (2021).

12. International Energy Agency, Methane tracker 2021. https://www.iea.org/reports/ methane-tracker-2021. Accessed 22 April 2021

13. Z. Liu et al., Global daily $\mathrm{CO}_{2}$ emissions for the year 2020. arXiv [Preprint] (2021). https://arxiv.org/abs/2103.02526 (Accessed 2 April 2021).

14. C. Le Quéré et al., Temporary reduction in daily global $\mathrm{CO}_{2}$ emissions during the COVID-19 forced confinement. Nat. Clim. Chang. 10, 647-653 (2020).

15. Z. Liu et al., Near-real-time monitoring of global $\mathrm{CO}_{2}$ emissions reveals the effects of the COVID-19 pandemic. Nat. Commun. 11, 5172 (2020).

16. A. J. Turner et al., Observed impacts of COVID-19 on urban $\mathrm{CO}_{2}$ emissions. Geophys. Res. Lett. 47, e2020GL090037 (2020)

17. D. Liu et al., Observed decreases in on-road $\mathrm{CO}_{2}$ concentrations in Beijing during COVID-19 restrictions. Atmos. Chem. Phys. 21, 4599-4614 (2021).

18. M. Buchwitz et al., Can a regional-scale reduction of atmospheric $\mathrm{CO}_{2}$ during the COVID-19 pandemic be detected from space? A case study for East China using satellite $\mathrm{XCO}_{2}$ retrievals. Atmos. Meas. Tech. 14, 2141-2166 (2021).

19. R. M. Duren et al., California's methane super-emitters. Nature 575, 180-184 (2019).

20. B. K. Lamb et al., Direct measurements show decreasing methane emissions from natural gas local distribution systems in the United States. Environ. Sci. Technol. $\mathbf{4 9}$ 5161-5169 (2015).

21. D. R. Lyon et al., Concurrent variation in oil and gas methane emissions and oil price during the COVID-19 pandemic. Atmos. Chem. Phys. 21, 6605-6626 (2021).

22. H. Tabuchi, Fracking firms fail, rewarding executives and raising climate fears The New York Times, 12 July 2020. https://www.nytimes.com/2020/07/12/climate/oilfracking-bankruptcy-methane-executive-pay.html. Accessed 28 July 2021.

23. National Oceanic and Atmospheric Administration, Annual mean global carbon dioxide growth rates (2021) https://gml.noaa.gov/ccgg/trends/gl_gr.html. Accessed 26 April 2021.

24. T. Shiraishi, R. Hirata, Estimation of carbon dioxide emissions from the megafires of Australia in 2019-2020. Sci. Rep. 11, 8267 (2021).

25. J. C. Fyfe et al., Quantifying the influence of short-term emission reductions on climate. Sci. Adv. 7, eabf7133 (2021).

26. N. S. Lovenduski et al., The ocean carbon response to COVID-related emissions reductions. Geophys. Res. Lett. 48, GL092263 (2021).

27. D. Wunch et al., The Total Carbon Column Observing Network. Philos. Transactions Royal Soc. A: Math. Phys. Eng. Sci 369, 2087-2112 (2011).

28. D. Wunch et al., "The Total Carbon Column Observing Network's GGG2014 data version" (Tech. Rep., California Institute of Technology, 2015). https://doi.org/10.14291/TCCON.GGG2014.DOCUMENTATION.R0/1221662. Accessed 23 October 2021.

29. P. O. Wennberg et al., TCCON data from Park Falls (US), Release GGG2014RO (TCCON data archive, hosted by CaltechDATA, Pasadena, CA, 2014). https://doi.org/10.14291/tccon.ggg2014.parkfalls01.R1. Accessed 2 April 2021.

30. V. Sherlock et al., TCCON data from Lauder (NZ), 125HR, Release GGG2014R0 (TCCON data archive, hosted by CaltechDATA, Pasadena, CA, 2014). https://doi.org/10.14291/tccon.ggg2014.lauder02.R0/1149298. Accessed 2 April 2021

31. D. F. Pollard, J. Robinson, H. Shiona, TCCON data from Lauder (NZ), Release GGG2014.R0 (TCCON data archive, hosted by CaltechDATA, Pasadena, CA, 2019). https://doi.org/10.14291/tccon.ggg2014.lauder03.R0. Accessed 2 April 2021.

32. National Oceanic and Atmospheric Administration, Despite pandemic shutdowns, carbon dioxide and methane surged in 2020 (2021). https://research.noaa.gov/ article/ArtMID/587/ArticleID/2742/Despite-pandemic-shutdowns-carbon-dioxideand-methane-surged-in-2020. Accessed 26 April 2021.

33. K. Miyazaki et al., Updated tropospheric chemistry reanalysis and emission estimates, TCR-2, for 2005-2018. Earth Syst. Sci. Data 12, 2223-2259 (2020).

34. A. J. Turner, C. Frankenberg, E. A. Kort, Interpreting contemporary trends in atmospheric methane. Proc. Natl. Acad. Sci. U.S.A. 116, 2805-2813 (2019)

35. M. Saunois et al., The global methane budget 2000-2017. Earth Syst. Sci. Data 12, 1561-1623 (2020).

36. J. McNorton et al., Role of $\mathrm{OH}$ variability in the stalling of the global atmospheric $\mathrm{CH}_{4}$ growth rate from 1999 to 2006. Atmos. Chem. Phys. 16, 7943-7956 (2016).

37. A. J. Turner, C. Frankenberg, P. O. Wennberg, D. J. Jacob, Ambiguity in the causes for decadal trends in atmospheric methane and hydroxyl. Proc. Natl. Acad. Sci. U.S.A. 114, 5367-5372 (2017).

38. J. L. Jimenez et al., Evolution of organic aerosols in the atmosphere. Science 326, 1525-1529 (2009).
39. A. S. Ansari, S. N. Pandis, Response of inorganic PM to precursor concentrations. Environ. Sci. Technol. 32, 2706-2714 (1998)

40. F. Dentener et al., The global atmospheric environment for the next generation. Environ. Sci. Technol. 40, 3586-3594 (2006)

41. P. J. Young et al., Pre-industrial to end 21st century projections of tropospheric ozone from the Atmospheric Chemistry and Climate Model Intercomparison Project (ACCMIP). Atmos. Chem. Phys. 13, 2063-2090 (2013).

42. G. Thornhill et al., Climate-driven chemistry and aerosol feedbacks in CMIP6 earth system models. Atmos. Chem. Phys. 21, 1105-1126 (2021).

43. Y. Zhao et al., Substantial changes in nitrogen dioxide and ozone after excluding meteorological impacts during the COVID-19 outbreak in mainland China. Environ. Sci. Technol. Lett. 7, 402-408 (2020).

44. S. K. Grange et al., COVID-19 lockdowns highlight a risk of increasing ozone pollution in European urban areas. Atmos. Chem. Phys. 21, 4169-4185 (2021).

45. J. D. Lee, W. S. Drysdale, D. P. Finch, S. E. Wilde, P. I. Palmer, UK surface $\mathrm{NO}_{2}$ levels dropped by $42 \%$ during the COVID-19 lockdown: Impact on surface $\mathrm{O}_{3}$. Atmos. Chem. Phys. 20, 15743-15759 (2020)

46. P. Messina et al., Global biogenic volatile organic compound emissions in the ORCHIDEE and MEGAN models and sensitivity to key parameters. Atmos. Chem. Phys. 16, 14169-14202 (2016)

47. M. M. Fry et al., The influence of ozone precursor emissions from four world regions on tropospheric composition and radiative climate forcing. J. Geophys. Res. Atmospheres 117, n/a-n/a (2012).

48. Y. Zhang et al., Contributions of world regions to the global tropospheric ozone burden change from 1980 to 2010. Geophys. Res. Lett. 48, e2020GL089184 (2021).

49. H. A. Parker, S. Hasheminassab, J. D. Crounse, C. M. Roehl, P. O. Wennberg, Impacts of traffic reductions associated with COVID-19 on Southern California air quality. Geophys. Res. Lett. 47, GL090164 (2020).

50. C. Ivey et al., Impacts of the 2020 COVID-19 shutdown measures on ozone production in the Los Angeles Basin. ChemRxiv [Preprint] (2020). https://dx.doi.org/ 10.26434/chemrxiv.12805367.v1 (Accessed 25 November 2020).

51. D. J. Rasmussen, J. Hu, A. Mahmud, M. J. Kleeman, The ozone-climate penalty: Past, present, and future. Environ. Sci. Technol. 47, 14258-14266 (2013)

52. US EPA, "Integrated science assessment (ISA) for particulate matter" (Tech. Rep EPA/600/R-19/188, U.S. Environmental Protection Agency, Washington, DC, 2019).

53. M. S. Hammer et al., Effects of COVID-19 lockdowns on fine particulate matte concentrations. Sci. Adv. 7, eabg7670 (2021).

54. S. Hasheminassab, N. Daher, B. D. Ostro, C. Sioutas, Long-term source apportionment of ambient fine particulate matter (PM2.5) in the Los Angeles Basin: A focus on emissions reduction from vehicular sources. Environ. Pollut. 193, 54-64 (2014).

55. S. E. Pusede et al. On the effectiveness of nitrogen oxide reductions as a control over ammonium nitrate aerosol. Atmos. Chem. Phys. 16, 2575-2596 (2016).

56. J. D. Berman, K. Ebisu, Changes in U.S. air pollution during the COVID-19 pandemic. Sci. Total Environ. 739, 139864 (2020).

57. S. Squizzato, M. Masiol, D. Q. Rich, P. K. Hopke, A long-term source apportionment of PM2.5 in New York State during 2005-2016. Atmos. Environ. 192, 35-47 (2018).

58. Z. Zheng, G. Xu, Q. Li, C. Chen, J. Li, Effect of precipitation on reducing atmospheric pollutant over Beijing. Atmos. Pollut. Res. 10, 1443-1453 (2019).

59. X. Zhao, Y. Sun, C. Zhao, H. Jiang, Impact of precipitation with different intensity on PM2.5 over typical regions of China. Atmosphere 11, 906 (2020).

60. Z. Jiang et al., Unexpected slowdown of US pollutant emission reduction in the past decade. Proc. Natl. Acad. Sci. U.S.A. 115, 5099-5104 (2018).

61. J. L. Laughner, R. C. Cohen, Direct observation of changing $\mathrm{NO}_{x}$ lifetime in North American cities. Science 366, 723-727 (2019)

62. D. T. Shindell, Y. Lee, G. Faluvegi, Climate and health impacts of US emissions reductions consistent with $2^{\circ}$ C. Nat. Clim. Chang. 6, 503-507 (2016)

63. S. E. Pusede, A. L. Steiner, R. C. Cohen, Temperature and recent trends in the chemistry of continental surface ozone. Chem. Rev. 115, 3898-3918 (2015).

64. A. P. Williams et al., Observed impacts of anthropogenic climate change on wildfire in California. Earths Futur. 7, 892-910 (2019).

65. T. Stocker et al., "Technical summary" in Climate Change 2013: The Physical Science Basis. Contribution of Working Group I to the Fifth Assessment Report of the Intergovernmental Panel on Climate Change, T. Stocker et al., Eds. (Cambridge University Press, Cambridge, UK, 2013).

66. S. Ridge, G. McKinley, Ocean carbon uptake under aggressive emission mitigation Biogeosciences 18, 2711-2725 (2021).

67. L. Brubaker, Women physicians and the COVID-19 pandemic. JAMA 324, 835-836 (2020).

68. J. L. C. Kok, Short-term trade-off between stringency and economic growth. COVID Econ 60, 172-189 (2020)

69. E. B. Barbier, Greening the post-pandemic recovery in the G20. Environ Resour Econ (Dordr) 76, 1-19 (2020).

70. Z. Chen, G. Marin, D. Popp, F. Vona, Green stimulus in a post-pandemic recovery: The role of skills for a resilient recovery. Environ Resour Econ (Dordr) 76, 1-11 (2020)

71. H. Cao, GEOS-Chem output of nitrate simulations for Laughner et al. 2021. Zenodo. https://zenodo.org/record/4849416. Accessed 22 October 2021.

72. M. Strohmeier, X. Olive, J. Lübbe, M. Schäfer, V. Lenders, Data from "Crowdsourced air traffic data from the OpenSky network 2019-20." Zenodo. https://zenodo.org/record/3928564. Accessed 31 March 2021

73. K. F. Boersma, et al., QA4ECV NO 2 tropospheric and stratospheric column data from OMI (2017). http://www.qa4ecv.eu/ecv/no2-pre/data. Accessed 11 November 2020.

74. J. van Geffen et al., Data from "S5P TROPOMI NO2 slant column retrieval: Method, stability, uncertainties and comparisons with OMI." TROPOMI. http://www. tropomi.eu/data-products/nitrogen-dioxide. Accessed 11 November 2020.

75. M. N. Deeter et al., Data from "A climate-scale satellite record for carbon monoxide: The MOPITT version 7 product." National Center for Atmospheric Research Atmospheric Chemistry Observations \& Modeling. https://www2.acom.ucar.edu/mopitt. Accessed 11 November 2020 
76. C. Li, N. A. Krotkov, J. Joiner, OMI/aura sulfur dioxide (SO2) total column 1-orbit L2 Swath $13 \times 24 \mathrm{~km}$ V003. Goddard Earth Sciences Data and Information Services Center Greenbelt, MD. https://doi.org/10.5067/Aura/OMI/DATA2022. Accessed 11 November 2020.

77. M. Schwartz, L. Froidevaux, N. Livesey, W. Read, MLS/Aura level 2 ozone (O3) mixing ratio V004. Goddard Earth Sciences Data and Information Services Center, Greenbelt, MD. https://doi.org/10.5067/Aura/MLS/DATA2017. Accessed 11 November 2020

78. G. Manney, M. Santee, L. Froidevaux, N. Livesey, W. Read, MLS/Aura level 2 nitric acid (HNO3) mixing ratio V004. Goddard Earth Sciences Data and Information Service Center, Greenbelt, MD. https://doi.org/10.5067/Aura/MLS/DATA2012. Accessed 11 November 2020.

79. Science Data Operations System Jet Propulsion Laboratory, OCO-2 level 2 geolocated $\mathrm{XCO} 2$ retrievals results, physical model, retrospective processing v10r. NASA Jet Propulsion Laboratory, Pasadena CA. https://doi.org/10.5067/6SBROTA57TFH. Accessed 2 April 2021.
80. T. Oda, S. Maksyutov, R. J. Andres, Data from "The open-source data inventory for anthropogenic $\mathrm{CO}_{2}$, version 2016 (odiac2016): A global monthly fossil fuel $\mathrm{CO}_{2}$ gridded emissions data product for tracer transport simulations and surface flux inversions." https://www.odiac.org/index.html. Accessed 2 April 2021.

81. Z. Liu et al., Data from "Global daily $\mathrm{CO}_{2}$ emissions for the year 2020." Tsinghua University, Beijing. https://carbonmonitor.org/. Accessed 2 April 2021.

82. National Oceanic and Atmospheric Administration, NOAA HRRR rapid refresh meteorology. https://rapidrefresh.noaa.gov/hrrr/. Accessed 11 November 2020.

83. J. C. Fyfe et al., Data from "Quantifying the influence of short-term emission reductions on climate." http://crd-data-donnees-rdc.ec.gc.ca/CCCMA/publications/ COVID19/. Accessed 17 May 2021.

84. California Air Resources Board, Air quality data California Air Resources Board, Sacramento, CA. https://www.arb.ca.gov/aqmis2/aqdselect.php. Accessed 11 November 2021 